\title{
Persistence of Prejudice: \\ Estimating the Long Term Effects of Redlining
}

\author{
Jacob Krimme] $\|^{*}$
}

This Draft: November 10, 2020

[First Draft: April 22, 2016]

\begin{abstract}
As part of a New Deal initiative to minimize home foreclosure, federal government officials and local real estate professionals graded each neighborhood in America's largest cities on its perceived credit risk. Using recently digitized maps that precisely show neighborhoods marked with red ink (highest risk) or yellow ink (slightly lower risk), I document that surveyors disproportionately assigned the most restrictive credit rating to neighborhoods with black residents. Nearly 90 percent of African Americans in 1940 lived in a census tract marked for credit redlining. Comparing credit-restricted "redlined" census tracts to adjacent "yellow-lined" tracts, I estimate the long-run effects of redlining on housing and neighborhood outcomes. Between 1940 and 1970, redlining was associated with large differential declines in housing supply and population density; homeownership rates and racial composition did not change differentially from their 1940 baseline though. Once discriminatory lending was outlawed during the mid-1970s, there was moderate convergence in homeownership rates and racial composition. However, housing supply and population density remain persistently lower in formerly credit-restricted census tracts relative to their credit-favored neighbors. Although African-American neighborhoods were much more likely to be redlined, I show the effects do not vary by a neighborhood's initial share of African American residents. Results also hold when restricting the sample to neighborhoods without any black residents in 1940 . Taken together, these findings suggest HOLC redlining impacted neighborhood housing supply and population independent of pre-war patterns of racial segregation.
\end{abstract}

Keywords: Redlining, housing supply, density, discrimination JEL Classification: O18, R21, R31, R38

${ }^{*}$ The Wharton School, University of Pennsylvania, email: jkrimmel@wharton.upenn.edu. For comments and suggestions, I thank Fernando Ferreira, Benjamin Keys, Joe Gyourko, Gilles Duranton, Jessie Handbury, Mariaflavia Harari, Maisy Wong, Corinne Low, Ben Hyman, Lindsay Relihan, Amine Ouazad, Don Davis, Henry Overman, Christian Hilber, and seminar participants at Wharton and the Urban Economics Association. I extend a special thank you to Robert K. Nelson of The Mapping Inequality Project and the University of Richmond's Digital Scholarship Lab for providing advanced access to HOLC map shapefiles in October 2016 before their public release. 


\section{Introduction}

This paper analyzes an important policy in the economic history of urban America, and one often linked to urban decay, segregation, and racial and spatial inequality: the implementation and repeal of neighborhood-specific mortgage lending guidelines. This practice is more colloquially known as redlining. As part of a New Deal initiative to minimize systemic risk of home foreclosure, a government-sponsored agency called the Home Owner's Loan Corporation (HOLC) surveyed America's 239 largest cities and rated each neighborhood's perceived credit risk on a grading scale of A through D (analogously coded green, blue, yellow, and red). The HOLC then created Residential Security Maps to guide private lenders' local standards and to influence Federal Housing Administration (FHA) criteria for selecting where to insure loans (Gordon, 2005). This regime remained legal until 1977, when redlining was outlawed by the Community Reinvestment Act (CRA) $\left.\right|^{1}$

As urbanist and activist Jane Jacobs wrote in The Death and Life of Great American Cities, "Credit blacklisting maps are accurate prophecies because they are self-fulfilling prophecies." Under this hypothesis, mortgage redlining formalized by HOLC appraisals created a vicious cycle of credit crunch and neighborhood decline in redlined neighborhoods compared to a virtuous cycle of favorable loan terms and reinvestment in higher-rated areas. Broadly speaking, this research setting presents a unique opportunity to uncover how changes in credit supplied to a neighborhood affect its long-term economic trajectory. More specifically though, tracing out the effects of HOLC redlining sheds new light on the essential trends of 20th century urban America, including urban decline (Rosenthal, 2008), segregation (Cutler, Glaeser, Vigdor, 1999), and inequality (Oliver and Shapiro, 2013).

Using geo-rectified versions of the original HOLC redlining maps and a new crosswalk linking census tracts from 1930-1940 to 1970-2010, I formally document the role of race in the selection of redlined areas, estimate long-run effects of redlining between 1940 and 1970, and test whether anti-redlining legislation reversed the economic fortune of previously divested areas. I first show the HOLC maps overwhelmingly marked America's black neighborhoods for credit redlining. Across my sample of 51 cities, 86 percent of African Americans lived in a redlined neighborhood in 1940, despite the fact that blacks constituted only 8 percent of the (sample) population. ${ }^{2}$ By contrast, only one in three whites (35 percent) lived in redlined areas despite making up over 90 percent of the 1940 sample population.

\footnotetext{
${ }^{1}$ Enacted in 1977, the CRA formally banned banks from basing lending decisions on a borrower's neighborhood. The CRA follows a suite of Civil Rights laws, including the Fair Housing Act of 1968, the Equal Credit Opportunity Act of 1974, and the Home Mortgage Disclosure Act of 1975. Unlike the previous legislation, the CRA requires any institution receiving FDIC insurance be evaluated by Federal banking agencies to ensure banks offer adequate credit to all neighborhoods in which they are chartered (https://www.federalreserve.gov/consumerscommunities/cra_about.htm). While redlining remained legal until 1977, it is not clear how long the HOLC maps remained relevant for lending policy. See Section 2.3 for a summary of the active historical debate regarding how the maps were used, for how long, and by whom.

${ }^{2} \mathrm{My} 51$ city sample includes about 34.4 million people, which covers about 46 percent of the US urban population in 1940 .
} 
To estimate the long-run effects of redlining, I use a difference-in-differences approach at the HOLC redlining boundaries comparing the most credit restricted (red, D-graded) census tracts to otherwise equal adjacent census tracts graded slightly more favorably (yellow, C-graded). My identification strategy attempts to overcome several challenges and sorting concerns which are widespread in the urban economics literature. Compared to the average neighborhood classified for conservative lending (Grade C, marked on the maps with yellow ink), the mean high-risk area (Grade D, marked with red ink) in 1940 had a higher population density, a higher proportion of black residents, and lower homeownership rates and house values. Because of selection on observables, I limit my analysis to neighborhoods directly bordering a Red-Yellow boundary line and use border fixed effects to compare adjacent neighborhoods receiving different credit worthiness grades. Narrowly focusing on boundary tracts not only creates much more observably similar treatment and control groups, but also controls for geographically related unobservables. At the red-yellow boundary line, I still find redlined areas had significantly more black residents at the onset of the policy in 1940. Indeed there is highly suggestive evidence that red lines were drawn precisely along pre-existing racially segregated areas. Despite this fact, treatment (redlined) and control (yellow-lined) neighborhoods at the red-yellow boundary lines did not differ significantly on other economic and demographic variables in 1940, such as housing supply, population density, labor force participation rate, or neighborhood share of foreign born residents. Still to address lingering selection concerns, my difference-in-differences specifications also control for initial differences in tract-level observables used in HOLC neighborhood appraisal. While there are likely unobservables correlated with historically African American neighborhoods for which I cannot account, the baseline results also hold when restricting the sample to neighborhoods that were homogeneously white in 1940.

The difference-in-differences identifying assumption is one of parallel trends: absent the HOLC's credit restrictive policies, the change in outcomes for redlined (treatment) areas would not have been different than the change in outcomes for the yellow-lined (control) areas. While parallel trends cannot be tested directly, I rely on data pre-dating the HOLC maps to examine trends between the treatment and control census tracts. Using 1930 census data available for subsample of cities, I do not find evidence of differential trends between 1930 and 1940 for several neighborhood quality measures including housing stock, population density, and homeownership rate. I do find a slight pre-trend in racial composition across the red-yellow borders, indicating that redlined border neighborhoods became about 2 percentage points more black between 1930 and 1940. However, this pattern reverses, rather than continues, during the treatment period.

Between 1940 and 1970, I find redlined neighborhoods saw large differential declines (around 20 percent) in housing supply and population density compared to adjacent neighborhoods that were rated slightly more favorably. Homeownership rates and racial composition did not change differentially from their 1940 baseline. Finally, I extend the difference-in-differences exercise through 2010 to determine if patterns that emerged along redline boundaries have persisted or reversed thanks fair housing legislation passed in the mid-1970s. After mortgage lending 
discrimination was formally outlawed, I find evidence of convergence in both homeownership rates and racial segregation between adjacent redlined and yellow-lined neighborhoods. However, I find redlining had persistently negative effects on housing supply and population density. Such discontinuities at a fine geographic level remain through 2010, despite the fact that the discriminatory lending policy has been outlawed for nearly 40 years.

Although historically black neighborhoods were far more likely to be redlined, I show in robustness exercises that the estimated effects of HOLC redlining are not driven by neighborhood racial composition in 1940. Indeed, the results hold at similar magnitudes when comparing adjacent boundary neighborhoods that were initially homogeneously white. This suggests that persistent differences in housing and neighborhood outcomes are driven in large part by market responses to HOLC ratings and not by unobserved forms of discrimination.

Despite strong anecdotal evidence of credit redlining for over 50 years (Sugrue, 2014), the HOLC's maps were only rediscovered by urban historian Kenneth Jackson in 1980 (Jackson, 1980; Hillier, 2003a). Recent technological advances have inspired a herculean effort to digitize and geo-reference the maps (Nelson et al., 2016), providing researchers across disciplines with geographically precise HOLC data. As such, only a fledgling literature has begun to study the legacy effects of redlining on a national scale $3^{3}$ Aaronson, Hartley, and Mazumder (2017) use the newly digitized maps to track the effects of HOLC grades on racial segregation, homeownership, and house values. On these measures, they find little persistent differences between red and yellow boundary neighborhoods, but they do uncover large persistent differences along the yellow-blue HOLC boundaries - a phenomenon they call "yellow-lining." Interestingly, they also find significant differences in credit scores across HOLC boundaries today. Appel and Nickerson (2016) and Anders (2018) use regression discontinuity designs to show redlining decreased home values and increased crime, respectively. Unlike these latter two papers which use only one year of outcome data, my methods trace out neighborhood dynamics between 1940 and 2010. Additionally, I document large differences in covariates and the HOLC boundaries in 1940, which calls into question the identifying assumptions of a regression discontinuity design.

In contrast to Aaronson, Hartley, and Mazumder, my results focus almost exclusively on the most credit-restricted (redlined) neighborhoods. While I validate their findings on the dynamics of racial segregation and homeownership, my results emphasize the large and persistent effects of the redlining maps on housing stock and population. Such effects are only found when comparing adjacent red and yellow-graded neighborhoods. These outcomes suggest that tying credit risk to neighborhood boundaries has a fundamental effect on the geography of capitalintensive projects and economic activity. Specifically, my results indicate that HOLC credit ratings had a first-order impact on whether and where homes were built. I interpret changes in

\footnotetext{
${ }^{3}$ There are two working papers I became aware of while working on previous versions of this draft: Aaronson, Hartley and Mazumder (2017) and Appel and Nickerson (2016). To the best of my knowledge, all three papers-Aaronson, Hartley, and Mazumder; Appel and Nickerson; and this paper-were developed independently and concurrently. I began this work in February 2016 as an independent research project in Fernando Ferreira's PhD course in Urban and Real Estate Economics.
} 
housing supply as an indication of which areas developers deemed areas worthy of investment. Because of the durability of housing, supply decisions made during the redlining period have a persistent effect on the stock of housing and density of economic activity today. As noted by Duranton and Puga (2014), "the fact that housing is durable has important effects on the evolution of cities. "4 $\mathrm{I}$ show this is also true for the economic trajectory of neighborhoods. Like Bleakley and Lin (2012), Davis and Weinstein (2002), and others studying the long-run effects of place-based shocks, I use population density as a proxy for economic activity. I find historically black and formerly redlined neighborhoods remain sparsely populated today, suggesting neighborhood desirability and economic activity is path dependent. These population patterns were shaped by sustained shifts in investment based on HOLC neighborhood credit ratings and were unchanged by anti-redlining fair housing initiatives.

Due to residential sorting (Bayer and McMillan, 2005; Bayer, Ferreira, McMillan, 2007; Sampson and Sharkey 2008) and differential access to credit (Charles and Hurst, 2002), the financial and racial background of borrowers are inextricably linked (Thompson and Suarez, 2015). This paper examines the historic and geographic roots of that link and contributes to literatures on place-based policy and persistence in urban economic settings. The field of economics has shown a growing interest in the geography of economic activity (Krugman, 1991), including quantifying the effects of place-based policies (Kline and Moretti, 2013; Matias, Gregory, and Kline, 2013) and examining the persistence of local economic shocks. This paper's methods of studying long-run economic impacts on either side of a border resembles Ahlfeldt et al.'s (2015) research on the economic development on either side of the Berlin Wall, Siodla's (2015) work examining the long-run redevelopment after the San Francisco earthquake and fire, and Hornbeck and Keniston's (2017) paper exploring the spillover effects from burned to neighboring unburned plots following the Boston fire. Studying the persistent effects of redlining is also related to the body of work on path dependence (Bleakley and Lin, 2012; Redding and Sturm, 2016) and the effect of shocks on cities in the long run (Davis and Weinstein, 2002).

This paper also contributes to work on the local economic impact of credit access (Black and Strahan, 2002) and federal housing policy (Harriss, 1951; Jackson, 1985; Gordon, 2005; Schill and Wachter, 1995). I find redlining created large disparities in adjacent neighborhoods' housing stock presumably through new construction and renovation on the favored side versus neglect and deterioration on the credit-restricted side. This neighborhood-level result is in line with the literature linking durability of housing to city-wide urban decline (Glaeser and Gyourko, 2005; Rosenthal, 2008). Studying mortgage redlining also advances our understanding of urban economic history by exposing one of the roots of residential segregation and suburbanization (Boustan, 2010; Shertzer and Walsh, 2016).

The paper proceeds as follows: section 2 introduces the institutional details surrounding the Home Owner's Loan Corporation maps and credit policies; section 3 describes the data;

\footnotetext{
${ }^{4}$ Others such as Glaeser and Gyourko (2005) and Rosenthal (2008) also speak to the connection between city growth and decline and the life-cycle of a city's housing stock.
} 
section 4 provides descriptives and stylized facts on the racial element of redlining; section 5 examines how the HOLC lines were drawn and the associated challenges to identification; section 6 provides the estimation strategy; section 7 presents the difference-in-differences results, including heterogeneous effects and robustness checks; section 8 concludes.

\section{Background}

\subsection{Setting and Motivation}

As part of a New Deal initiative to minimize systemic risk of home foreclosure, a governmentsponsored agency called the Home Owner's Loan Corporation (HOLC) surveyed America's largest 239 cities and rated each neighborhood's perceived credit risk on a grading scale of A through D (analogously coded green, blue, yellow, and red). The HOLC advised that the third graded areas (marked with yellow ink) were in decline and that "good mortgage lenders [should be] more conservative." Alternatively, the agency suggested "some mortgage lenders may refuse to make loans" in the fourth graded areas. These fourth graded areas were outlined and colored red on the HOLC's maps - hence the term "redlining." In making the maps, the HOLC consulted with bankers and builders in each city (thousands of local experts in total) in order to influence local lending standards (Wilder, 2000; Greer, 2012). The maps and neighborhood appraisal methods were also shared with the Federal Housing Administration (Hillier, 2003; Light, 2010) to help set neighborhood-level criteria for FHA mortgage insurance (Gordon, 2005). Ultimately, the practice of "redlining" was finally outlawed following the passage of several key pieces of Civil Rights legislation culminating with the Community Reinvestment Act (CRA) in 1977. The CRA made it illegal for banks to base lending decisions on borrower's neighborhood and in fact encouraged banks to meet the needs of the formerly credit constrained areas $5^{5}$ Importantly distinct from the Fair Housing and Equal Credit Opportunity Acts, which protected individuals from discrimination in the mortgage markets, the CRA's explicit purpose was to increase the flow of capital to disinvested neighborhoods.

Despite the red ink demarcations specific to the HOLC maps, the term "redlining" in common parlance has come to represent any race or location-based discriminatory lending in general ${ }^{6}$ As a result, race-based and location-based lending policies have become the catchall cause of urban decay, disinvestment in cities, residential segregation, and a widening racial-wealth gap (Badger (2015); Coates (2014); Greer (2013). While there may ultimately be truth to this view, such conclusions do not yet rest on firm empirical ground:7

\footnotetext{
${ }_{5}^{5}$ https://www.occ.treas.gov/topics/community-affairs/publications/fact-sheets/fact-sheet-cra-reinvestmentact.pdf

${ }^{6}$ As a result, examples of lending discrimination potentially unrelated to the original HOLC Residential Security Maps, however structural or representative of routine discriminatory practices (historical or ongoing) within the real estate industry, have fallen under this umbrella term. For the purposes of this paper which studies specifically the legacy of the HOLC Residential Security Maps, redlining will refer to neighborhoods designated as Grade D by the HOLC rather than the act of discriminatory lending in general.

${ }^{7}$ There is in fact ample evidence in 1930s-40s FHA underwriting manuals that the federal government sought to create separate mortgage markets for black and white Americans and maintain racially homogeneous neighborhoods, see for example Racial Content of FHA Underwriting Practices. 1934 - 1962 http://archives.ubalt.edu/aclu/pdf/Plex48.pdf
} 


\subsection{Institutional Details on the HOLC}

After roaring through the 1920s, the American housing market crumbled following the stock market crash in December 1929. The "Great Contraction" from 1929 to 1933 led to a 30 to 40 percent fall in housing prices (Fishback et al., 2010). Hundreds of thousands of homeowners defaulted and thousands of mortgage lending institutions failed, which created a "self-reinforcing cycle of delinquency, foreclosure, forced property sales, and decreases in home values" (Courtemanche and Snowden, 2011). As part of the New Deal, the Roosevelt Administration established the Home Owner's Loan Corporation (HOLC) in 1933 to purchase distressed mortgages from private lenders and also issue new mortgages directly to troubled borrowers. Along with the FHA, the HOLC helped revolutionize the home mortgage market by standardizing the longterm, low interest rate, amortized mortgage. Importantly, these would be the only types of mortgages "eligible for insurance programs that were promulgated by the Federal Deposit Insurance Corporation (FDIC)" (Greer, 2012 p. 278). The standardization of the long-term mortgage instrument forced lenders-now with fewer degrees of freedom-to rely on a coarse shorthand, like neighborhood characteristics, to evaluate individual mortgage risk.

In late 1935, the HOLC's parent organization (the Federal Home Loan Bank Board, or FHLBB) established the City Survey Program to appraise real estate risk levels in each of the country's 239 cities with over 40,000 residents. Between 1935 and 1940, HOLC staff and local realtors surveyed these cities and produced detailed Residential Security Maps of each neighborhood (Hillier, 2003). The goal was to produce formal and consistent appraisal methods across cities, such that "one appraiser's judgment of value would have meaning to an investor located somewhere else" (Jackson, 1980). Likewise, Greer (2012) cites two purposes for the Residential Security Maps: (1) to direct underwriting criteria of the FHLBB; and (2) to provide all other newly-regulated financial institutions with a detailed guide for making future mortgage loan investment decisions. In this way, the Residential Security grades were guidelines for not only government lenders, but also potentially for private regulated banks who sought mortgage insurance from federal underwriters. Formally, the explanations of each of the Residential Security grades as well as the HOLC's instructions to local financiers is summarized below:

"Four classifications are used as indicated by the legend, namely: First, Second, Third and Fourth grades. The codes letters and colors are A, B, C, and D, and Green, Blue, Yellow and Red respectively. In establishing the grade of an area, such factors as these are considered [including the] economic stability of the area [and] social status of the population.

The First grade of A areas are "hot spots"; they are not fully built up...The Second grade or $\mathrm{B}$ areas, as a rule, are completely developed. They are like a 1935 automobile - still good, but not what the people are buying today who can afford a new one...The Third grade or $\mathrm{C}$ areas are characterized by age, obsolescence, and change of style; expiring restrictions or lack of them; infiltration of a lower grade population.

Good mortgage lenders are more conservative in the Third grade or $\mathrm{C}$ areas and hold loan commitments under the lending ration for the $\mathrm{A}$ and $\mathrm{B}$ areas. The fourth grade or $\mathrm{D}$ areas...are characterized by detrimental influences in a pronounced degree, undesirable population of an infiltration of it... The areas are broader than the so-called slum districts. Some mortgage lenders may refuse to make loans in these neighborhoods and others will lend only on a conservative basis. 
These maps and descriptions have been carefully checked with competent local real estate brokers and mortgage lenders, and we believe they represent a fair and composite opinion of the best qualified local people. ${ }^{8}$

In conducting the city surveys and appraisals, the FHLBB and HOLC determined neighborhood sizes and boundaries according to the consensus of the day. That is, determining where one neighborhood ended and another began could depend on physical geography, major roads, reputation at the time, etc. Once the neighborhood boundaries were determined, the HOLC surveyed each one, "documenting the condition of occupation, income, and ethnicity of the inhabitants and the age, type of construction, price range, sales demand, and general state of repair of the housing stock" (Jackson, 1980), and then finally assigned each one a Residential Security Grade. Baltimore's Residential Security Map is reproduced below (Figure 1).

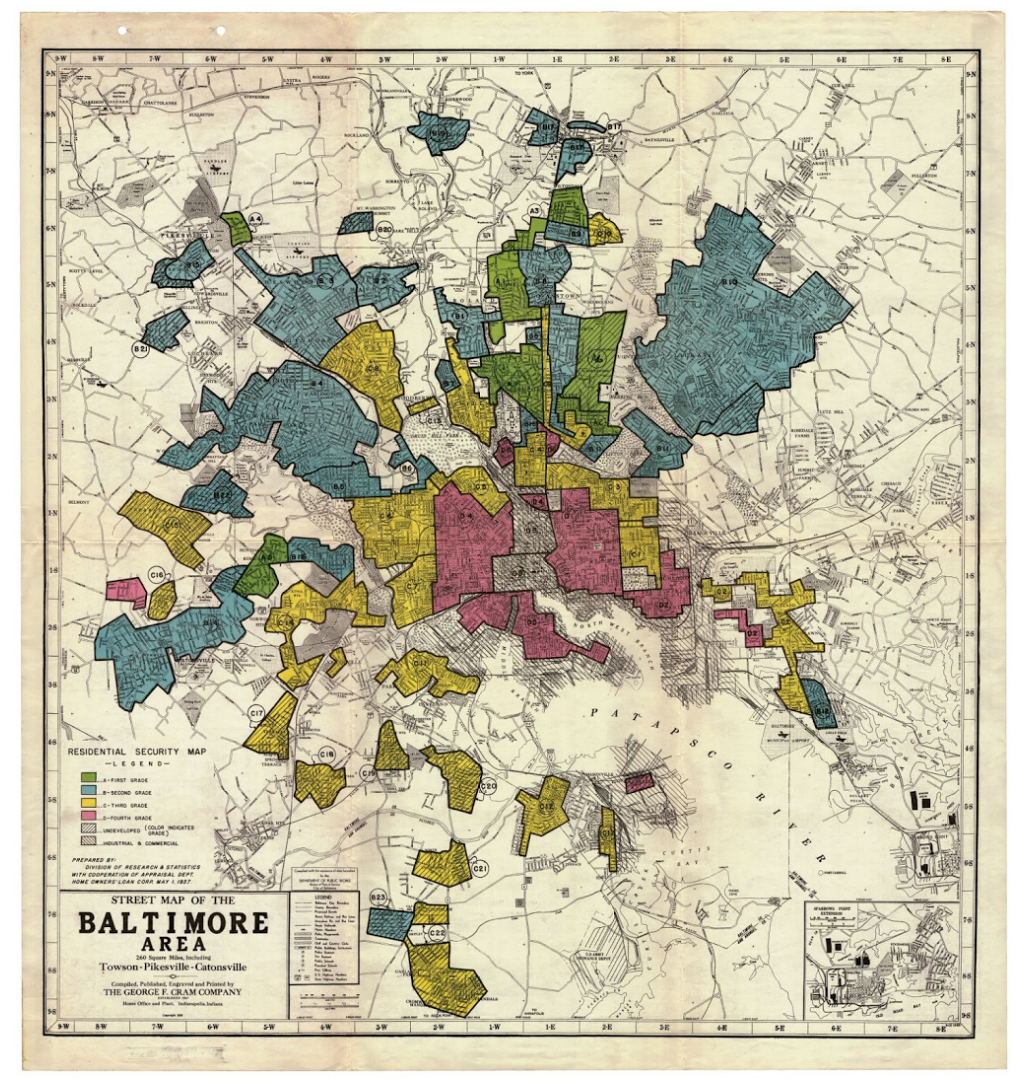

Figure 1: Baltimore's map produced by the HOLC and local private mortgage lenders, May 1, 1937

In an attempt to mitigate perceived risk nationwide, the HOLC's Residential Security Maps were designed to codify lending standards across markets and to demarcate neighborhoods worthy of investment by private and public developers, lenders, and the Federal Housing Administration (FHA). Moreover, the maps were drawn with the explicit intention to maintain racial and social homogeneity within neighborhoods, as keeping races and/or social classes separate was seen as a way to preserve neighborhood stability and property values at the time. Such sentiments are apparent both in FHLBB and FHA manuals of the time9 9 As historian Louis

\footnotetext{
${ }^{8}$ Residential Security Map of Baltimore, MD 1937 https://jscholarship.library.jhu.edu/handle/1774.2/32621.

${ }^{9}$ see Richard C. Stearns, Memorandum, Racial Content of FHA Underwriting Practices 1934-1962
} 
Lee Woods (2012) writes: "While the HOLC did not create racial and socioeconomic lending bias, it certainly helped nationalize the practice" (p. 1038).

\subsection{How Were the Maps Used?}

While there is broad consensus (Greer, 2012; Wilder, 2000; Jackson, 1980) that local private sector bankers and real estate experts consulted in making the maps, the historical literature is somewhat divided on whether private entities used the maps to make lending decisions. Hillier (2003) and Greer (2012) argue the maps were not shared with private-sector lenders, though Greer acknowledges that HOLC director Corwin Fergus publicly stated that 5,000 private real estate agents and bankers were involved in developing the maps. According to others, the maps became the primary sources used secretly by local real estate financiers to determine mortgage terms, loan eligibility, and mortgage insurance availability throughout the post-war period (Sugrue, 2014; Jackson, 1980). Woods (2012) argues HOLC appraisals were used by subsidiary banking agencies throughout the entire federal banking system, including the FHA, the Federal Savings and Loan Insurance Associations, and 12 regional Federal Home Loan Banks located across the country 10 Crucially, the historical literature agrees that the FHA and HOLC had close ties (Light, 2010) and that the FHA had access to the Residential Security Maps (Hillier, 2003).

Despite a lack of explicit documentation, there is strong suggestive evidence the maps' residential security grades and instructions were used as guidelines, albeit not legal requirements. It is also not known for how long the maps remained relevant to the FHLB, the FHA, or private sector lenders. Due to a lack of historical bank and mortgage lending data, this paper will not resolve any of these debates. Instead, an important contribution of this paper is to highlight the strong correlation between the HOLC redlining boundaries and new housing construction. The pattern of new housing only on the credit-favored side of the boundary provides suggestive evidence that HOLC neighborhood redlining influenced private sector behavior whether or not the maps were consulted directly, which likely occurred through the channel of where homes were eligible for mortgage insurance. Such a narrative is consistent with Greer's 2012 argument whereby the maps set de facto boundaries for new home construction. Because of the new longterm mortgage and because mortgage insurance required certain minimum building standards, the New Deal and post-War mortgage market "would direct lending toward new construction" (Greer, 2012, p. 292). The maps, therefore, created "new channels in which mortgage capital would flow across metropolitan space."

http://archives.ubalt.edu/aclu/pdf/Plex48.pdf.

${ }^{10}$ By the late 1930s, the FHLBB's monthly reports "reached an extremely representative cross section of the whole field of urban home-mortgage finance and reflected the interests not only of the home-financing institutions but also of appraisers, real-estate dealers, material suppliers...and of the many other people and institutions which require useful and accurate information upon current trends in the urban home market." (Fifth Annual Report, FHLBB, 1936-1937, 20 (via Woods, 2012)). By 1940, FHLBB had become "the largest coordinated mortgage credit reserve in US history, and all of its members had adopted the HOLC appraisal practices" (Woods, 2012). By 1948, the Federal Home Loan Banking System held 90 percent of the nation's total savings and loan assets (Woods, 2013) 


\subsection{Related Literature}

There is a small literature identifying the immediate effects of HOLC neighborhood classification, including Hillier (2003 a,b; 2005); Crossney and Bartelt (2005 a, b), and Brennan (2015). In a series of papers, Hillier examines the Philadelphia HOLC map and lending practices and determines that though racial composition was a significant predictor of map grades, the HOLC did continue to make loans in the redlined neighborhoods. In their study of New Deal lending in Pittsburgh and Philadelphia, Crossney and Bartelt (2005 b) show the appraisal and lending behavior was not necessarily consistent across cities, suggesting "local context is important for studying the HOLC as a public policy instrument." Both sets of papers analyze one or only a small handful of cities, however.

Because the HOLC Residential Security maps have only recently been digitized and made publicly available (Nelson et al., 2016), literature on the long-term effects of widespread HOLC redlining is scarce. Research most closely related to this project are concurrent work by Aaronson, Hartley, and Mazumder (2017), Appel and Nickerson (2016), and Anders (2018)

Like this project, Aaronson, Hartley, and Mazumder (AHM) (2017) examine neighborhoods on opposite sides of HOLC boundaries and trace out the effects of redlining from 1940 through 2010. In a triple-difference-in-differences framework, they compare differences across existing boundaries to differences across "counterfactual" boundaries over time. Much of their analysis focuses on the differences between second and third graded areas, rather than third and fourth grade areas as I propose. Between HOLC grade B-C (second-grade to third-grade) boundaries, they find evidence of a long-run decline in homeownership, house values, and credit scores in lower graded areas that persists today ${ }^{11}$ However, they only find persistent effects across C-D (Red-Yellow, or third grade-fourth grade) boundaries on the credit score measure and not on housing variables. Like my paper, they find racial segregation and differences in homeownership rates between redlined and yellow-lined tracts declined after 1970 .

Appel and Nickerson (2016) apply a regression discontinuity design exploiting HOLC boundaries and find that redlined areas have nearly 5 percent lower home prices in 1990 relative to adjacent control tracts. Unlike my analysis, Appel and Nickerson pool across all HOLC grades, which implicitly imposes a common treatment effect across HOLC ratings. They also examine long-run outcomes only in 1990, rather than tracing out the long-run dynamics before, during, and after the policy was in effect. Anders (2018) conducts both a spatial within-city RD and an across-city $\mathrm{RD}$ to examine the long-run effects of redlining on crime. In the within-city analysis, he finds redlining is associated with incresed crime in present-day Los Angeles. The cross-city analysis exploits a discontinuity in which cities were mapped by the HOLC, and he finds redlining increased the overall volume of city-level crime.

\footnotetext{
${ }^{11} \overline{\text { Though I do not focus on the "yellow-lining" }}$ phenomenon proposed by Aaronson, Hartley, and Mazumder, my findings in Appendix 9.12 validate theirs on racial segregation and homeownership across B-C boundaries.
} 


\section{Data}

I rely on "geo-rectified" digitized versions of the HOLC Residential Security Maps provided by the Mapping Inequality Project (a project of the University of Richmond's Digital Scholarship Lab ${ }^{12}$ and decennial US census data. The Mapping Inequality Project provides downloadable ArcGIS shapefiles for over 150 cities. Each consists of a set of polygons of the HOLC-defined and graded neighborhoods. Unlike today, the entire country was not mapped for census tracts in 1940 (or earlier), so the number of cities for which HOLC polygons are available exceeds the number of cities for which census tract level data exist. As a result, the full sample includes 6,794 tracts from 51 cities, which account for about 46 percent of the 1940 urban population. The sample includes 9 of the top 10 and 20 of the top 25 most populated cities in 1940. A list of cities in the sample can be found in the appendix.

The majority of cities were surveyed between 1937 and 1940 13 For instance, the HOLC map for Chicago, the largest city in my sample (New York's five boroughs each had separate maps), was not completed until April 1940. As such, I treat the 1940 census data as coincident with the onset of the policy, or the "pre-period" for the purposes of the long-term analysis. I do this both because of data limitations and to better align neighborhoods. First, using 1940 rather than 1930 as my baseline allows me include 51 rather than just 19 cities because fewer cities were mapped for census tracts in 1930. Second, the 1940 census data, compared to 1930, is likely a better representation of neighborhoods as they were surveyed by the HOLC in the late 1930s through early 1940. In densely populated areas in major cities, HOLC neighborhood polygons usually contain several tracts. Importantly, the boundaries of the HOLC polygons often but not always line up with boundaries of the 1940 census tracts.

To determine each tract's HOLC grade, I first compute from the geo-rectified maps the percentage of each tract's area covered by each HOLC grade. I then assign each tract its creditworthiness grade according to the plurality HOLC grade of that tract ${ }^{14}$ In order to conduct the border analysis of neighboring tracts, I determine for each tract the nearest HOLC polygon boundary associated with a change in HOLC grade. More specifically, I use the HOLC neighborhood polygon shapefiles to create a GIS dataset identifying all Red-Yellow border line segments for each city in my sample ${ }^{15}$ For each border line segment, I determine all census tracts within 3 miles of the border. Here I use the tract's extant boundaries, not its centroid coordinates, such that if a tract borders a Red-Yellow boundary line segment, its distance to

\footnotetext{
${ }^{12}$ Robert K. Nelson, LaDale Winling, Richard Marciano, Nathan Connolly, et al., "Mapping Inequality," American Panorama, ed. Robert K. Nelson and Edward L. Ayers, accessed April 6, 2016, https://dsl.richmond.edu/panorama/redlining/.

${ }^{13}$ In email exchanges with me, professor and co-creator of the Mapping Inequality Project Robert Nelson indicated that the majority of the cities were surveyed in 1937 or later.

${ }^{14}$ In the full sample, the median tract's plurality coverage rate is 67 percent, while among red and yellow graded areas, the median coverage rate is 69 percent. In other words, the HOLC grade I assign covers about two thirds of the tract's area, on average.

${ }^{15}$ I use border line segments, rather than entire polygon border lines, in the main analysis in order to group tracts for a finer geographic fixed effect. A polygon border fixed effect would group together all tracts on either side of that boundary, while an HOLC border line segment fixed effect treats each line segment of a polygon boundary as a separate identifier. See figures in Section 5 for more detail
} 
the boundary is zero. I then use the unique line segment identifier to determine which tracts border which Red-Yellow boundary. Finally, I group census tracts based on the longest border that they share with an HOLC boundary line segment.

The vast majority of tracts (5,026 of the 6,794 in my full sample) are graded either D (Red) or C (Yellow). These tracts accounted for about $36 \%$ of the urban population in 1940 but only 9 percent of the urban population in 2010 ${ }^{16}$ Additionally, the neighborhoods coded red or yellow account for about 72 percent of the full sample's population in 1940. The main analysis compares census tracts bordering a Red-Yellow HOLC boundary line. There are 2,055 red-yellow border tracts in total (918 of which are majority red and 1,137 are majority yellow) located across 1,012 borders in 51 cities. Per city, my analysis captures on average 39 tracts located across 19 borders. In 1940, about 47 percent of all people living in red or yellow areas lived in a boundary tract (the population living in red-yellow boundary neighborhoods make up about 34 percent of my full sample population in 1940).

The full panel includes data from the 1940, 1970, 1980, 1990, 2000, and 2010 decennial censuses, via NHGIS (Manson et al., 2017) and Brown University's Longitudinal Tract Data Base (Logan et al., 2014). To test for pre-trends, I use 1930 census tract level data to create a 1930 to 2010 sub-panel. Even fewer places were mapped for census tracts in 1930, so the sub-panel contains data for only 19 cities 17 The census data allow me to construct time series of tract level population, housing supply, homeownership rate, race of inhabitants, occupancy status (occupied or vacant), median house value, and median rental price (median values through 2000 only). The 1940 census also includes several variables useful for backing out of the determinants of the HOLC grading system, such as male labor force participation rate, percent of foreign-born residents, median years of schooling, percent of homes in disrepair, and percent of households with radio, refrigerators, and/or heating.

To overcome the fact that census tract boundaries change over time, I use a series of crosswalks to arrive at a constant geography. I use 1940 tract boundaries as my baseline because these likely reflect neighborhoods contemporaneous with the HOLC surveys of the late 1930s. I create this common geography across these census waves in two steps. First, I use Brown University's Longitudinal Tract Data Base (LTDB) for a block-by-block crosswalk to convert the 1970 through 2000 data into the 2010 census tract boundaries 18 With the common geography of 2010 in hand, I then overlay the 2010 boundaries on the 1940 census tract shapefiles and, using tract area intersections, create my own 2010-to-1940 crosswalk. I use a methodology similar to the LTDB to re-weight the 1970-2010 tracts to their 1940 equivalents.19 I also create a 1930 to 1940 crosswalk using the same method. Because 1930 and 1970-2010 census tracts are re-weighted according to their land area overlap with 1940 tract boundaries, the crosswalk

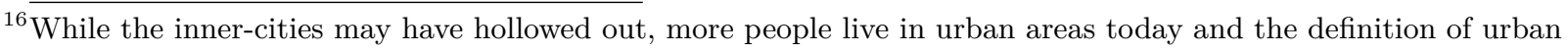
has expanded since 1940. That is, measuring the US urban population over time is not comparing constant geographies.

${ }^{17}$ See appendix for list of cities in 1930 sample.

${ }^{18} \mathrm{https}$ ///s4.ad.brown.edu/projects/diversity/Researcher/Bridging.htm

${ }^{19}$ https://s4.ad.brown.edu/projects/diversity/Researcher/LTBDDload/DataList.aspx
} 
exercise introduces some statistical noise to the time series data. As a result, my point estimates using time series data may be biased downward due to classical measurement error.

\section{Who was Redlined?}

Table 1 below shows several descriptives of 1940 census tracts by their assigned HOLC Residential Security Map Grade. Over 70 percent of tracts were assigned a grade of C or D (Yellow or Red); these tracts housed nearly 80 percent of the sample population in 1940. Furthermore, lower graded tracts were more likely to have higher population density and fraction of black residents and lower homeownership rates and housing values (not shown). The fact that red tracts (in the pooled sample) were 17.5 percent black, while yellow tracts were only 1.81 percent black hints at both the highly segregated nature of urban living in the 1930s-40s and the nonrandom assignment of HOLC grades. In some cities, there is anecdotal evidence that the presence of one black family automatically triggered an HOLC grade of D ${ }^{20}$ Indeed Greer (2012) used the HOLC Security Maps and Area Descriptions to confirm this was the case in Chicago.

Table 1: Summary Statistics, 1940

\begin{tabular}{|c|c|c|c|c|c|c|c|c|}
\hline \multirow[t]{2}{*}{ HOLC Grade } & \multicolumn{2}{|c|}{ Share of: } & \multirow[t]{2}{*}{ Area(sqmi) } & \multirow{2}{*}{$\begin{array}{c}\text { Miles to } \\
\text { City Center }\end{array}$} & \multirow{2}{*}{$\begin{array}{c}\text { Housing } \\
\text { Units }\end{array}$} & \multirow{2}{*}{$\begin{array}{c}\text { Population } \\
\text { Density }\end{array}$} & \multirow{2}{*}{$\begin{array}{c}\text { Homeownership } \\
\text { Rate }\end{array}$} & \multirow{2}{*}{$\begin{array}{r}\text { Percent } \\
\text { Black }\end{array}$} \\
\hline & Tracts & Population & & & & & & \\
\hline None/Unmapped & 8.02 & 4.3 & 8.83 & 8.42 & 756 & 323 & 35.6 & 4.03 \\
\hline Green & 3.59 & 2.77 & 2.22 & 6.45 & 1,174 & 1,761 & 53.5 & 2.14 \\
\hline Blue & 14.4 & 14.5 & .876 & 5.59 & 1,558 & 5,819 & 41.9 & 1.11 \\
\hline Yellow & 37.6 & 39.6 & .865 & 5.31 & 1,590 & 6,171 & 34.8 & 1.81 \\
\hline$\underline{\text { Red }}$ & 36.4 & 38.8 & .602 & 3.34 & 1,566 & 8,983 & 21.1 & 17.5 \\
\hline Mean & & & 2.6 & 4.96 & 1,329 & 4,611 & 37.4 & 5.32 \\
\hline
\end{tabular}

Table 2 further highlights the racial element of redlining. The table shows the 12 largest cities' black and white population share and the share of each race's population residing in a redlined neighborhood. See Appendix 9.2 for the same table including all 51 sample cities. Chicago, for instance, was just 8 percent black in 1940; but 98 percent of Chicago's black residents lived in an area redlined on the HOLC map ${ }^{21}$ Despite making up just 8 percent of the sample population of 34.4 million people across 51 cities, 86 percent of blacks in 1940 lived in a neighborhood marked for credit redlining by the HOLC. By contrast, only one in three whites in 1940 lived in the most credit-restricted areas despite making up three quarters of the sample population.

Figure 2, Panel A plots data from Table 2 for the full sample of cities. It shows kernel density plots for within-city share of black residents redlined (solid line) and share of white residents redlined (dotted line). Densities are weighted by city population in 1940. The figure

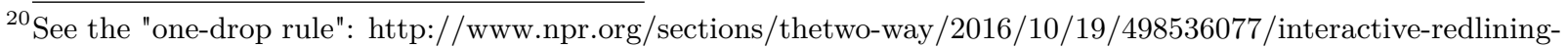
map-zooms-in-on-americas-history-of-discrimination

${ }^{21}$ Because I do not have micro data, I estimate this by dividing the number of black residents residing in census tracts that were plurality redlined by the total number of black residents in the city. Another way of stating this is: 98 percent of Chicago's black residents lived in census tracts that were mostly colored red on the HOLC map.
} 
Table 2: Redlining and Race in America's Largest Cities (1940)

\begin{tabular}{|c|c|c|c|c|c|}
\hline \multirow[t]{2}{*}{ City } & \multirow[t]{2}{*}{ Population } & \multicolumn{2}{|c|}{ Black } & \multicolumn{2}{|c|}{ White } \\
\hline & & Population Share & Share Redlined & Population Share & Share Redlined \\
\hline Chicago, Illinois & $3,400,000$ & 8 & 98 & 92 & 35 \\
\hline Los Angeles, California & $2,790,000$ & 3 & 86 & 95 & 26 \\
\hline Brooklyn, New York & $2,700,000$ & 4 & 90 & 96 & 46 \\
\hline Detroit, Michigan & $2,070,000$ & 8 & 94 & 92 & 37 \\
\hline Philadelphia, Pennsylvania & $1,930,000$ & 13 & 89 & 87 & 50 \\
\hline Manhattan, New York & $1,890,000$ & 16 & 90 & 83 & 58 \\
\hline Pittsburgh, Pennsylvania & $1,410,000$ & 6 & 66 & 94 & 26 \\
\hline Bronx, New York & $1,390,000$ & 2 & 81 & 98 & 46 \\
\hline Queens, New York & $1,300,000$ & 2 & 48 & 98 & 12 \\
\hline Cleveland, Ohio & $1,230,000$ & 7 & 94 & 93 & 34 \\
\hline St.Louis, Missouri & $1,090,000$ & 11 & 82 & 89 & 24 \\
\hline Baltimore, Maryland & 860,000 & 19 & 90 & 81 & 33 \\
\hline TOTAL (51 Cities) & $34,400,000$ & 8 & 86 & 92 & 35 \\
\hline
\end{tabular}

shows two very different distributions. The distribution for the share of black residents redlined is highly skewed, with most of the mass around 90 percent. The population weighted median is 89 percent; the mean is 81 percent with a 20 percent standard deviation. In other words, for the average city, about 9 in 10 African Americans lived in an area that was redlined in 1940. This ratio is remarkably consistent across cities. The share of whites redlined is distributed rather normally across cities with the mean and median of 35 percent and a standard deviation of 13.6 percent.

Panel B of Figure 2 repeats this exercise for black and white residents living in "Yellow-lined" (Grade C) neighborhoods in 1940. Around 10 percent of black residents lived in yellow-lined neighborhoods in most cities compared to about half of the city's white residents. Recall from Table 1 that nearly 80 percent of the sample lived either in a redlined or yellow-lined neighborhood, with about an equal proportion living in redlined (38.8 percent) as yellow-lined (39.6 percent) areas. While white residents were roughly split between Grade C and Grade D neighborhoods, black residents nearly always lived on the lower-rated, credit-restricted side of the boundary. This speaks to both the high degree of segregation at the time and the race-based selection of the credit ratings.

Figure 2: HOLC Grading and Race, City-Level Density Plots

\section{Panel $A$}

Share of Redlined Residents by Race, 1940

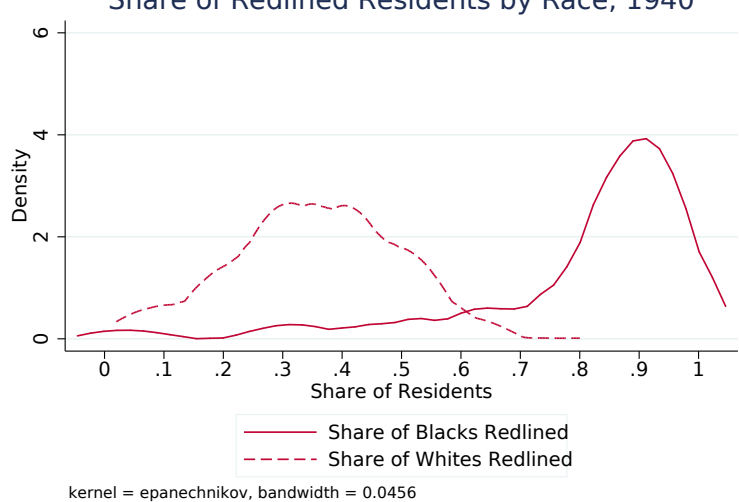

Panel $B$

Share of Yellow-lined Residents by Race, 1940

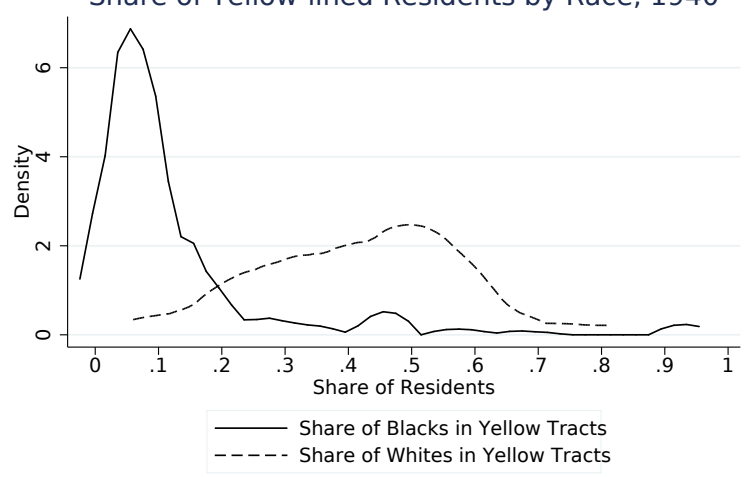

kernel $=$ epanechnikov, bandwidth $=0.0242$ 


\section{$5 \quad$ Identification Challenges}

In an ideal natural experiment, redlining beginning with the maps' introduction in the late 1930s and ending with the enactment of anti-redlining legislation in 1977 would represent a randomly assigned, exogenous (and unanticipated) shock to credit availability. Of course the HOLC credit grades were not randomly assigned, initial economic conditions differed significantly across the risk grades, and lending discrimination was likely rampant-although not geographically precise. So rather than a regression discontinuity or a general difference-in-difference, I rely on a difference-in-differences at the HOLC redline boundary to evaluate the changes over time between census tracts of different credit ratings.

I categorize the 1940 census data as "pre-redlining" for the purposes of the long-term analysis. The majority of cities were surveyed between 1937 and 1940. Treating 1940 as coincident with the onset of redlining assumes that, for those cities that were surveyed in the late 1930s, the policy did not have significant effects on neighborhoods in the several years between the production of the maps and the 1940 census. This is not worrisome as the purpose of this project is to identify long-run, not short-run effects. If there were negative effects in these first few years, my analysis will underestimate the impact of redlining. Using 1940 rather than 1930 as my baseline allows me to expand expand my sample to more cities, which improves power and reliability 22 Additionally, 1940 tracts a better align neighborhoods with HOLC boundaries, which minimizes within-city measurement error.

The major threats to identification are concerns of highly-selected, non-random HOLC classification, potential violations of the parallel trends assumption, and the confounding policies or events after 1940 unrelated to HOLC redlining that might bias the results. Analyzing initial conditions close to the HOLC grade boundaries reveals tracts were selected against based on certain observables. Figure 3 below plots a local polynomial regression of the share of black residents in 1940 by distance to the nearest red/yellow HOLC boundary. Negative values correspond to neighborhoods on the red (Grade D) side of the boundary while positive values are associated with those on the yellow (Grade C) side. The figure includes all tracts within 0.5 miles of the boundary (3,670 in total). The shaded gray areas represent 95 percent confidence intervals. From the figure's sharp discontinuity, we see that tracts with any non-negligible share of black residents were almost always graded least favorably by the HOLC. At the boundary, tracts coded red are about 15 percent black in 1940. On the other side of the border, neighborhoods are about 1-2 percent black. This graphic is consistent with the d racial selection implied by Figure 2's city-level density plots.

While Figure 3 documents stark racial segregation in 1940, it obfuscates the fact that other socioeconomic variables were also highly correlated with race. Figure 4 below repeats these local polynomial regressions for other economic and demographic neighborhood characteristics. Despite the fact that neighborhoods directly on either side of the boundary differed significantly on racial composition, they were more similar on other observables, such as the number of housing

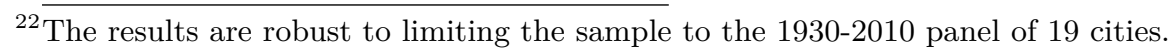


Figure 3: Percent Black at the Red-Yellow Border, 1940 (raw data)

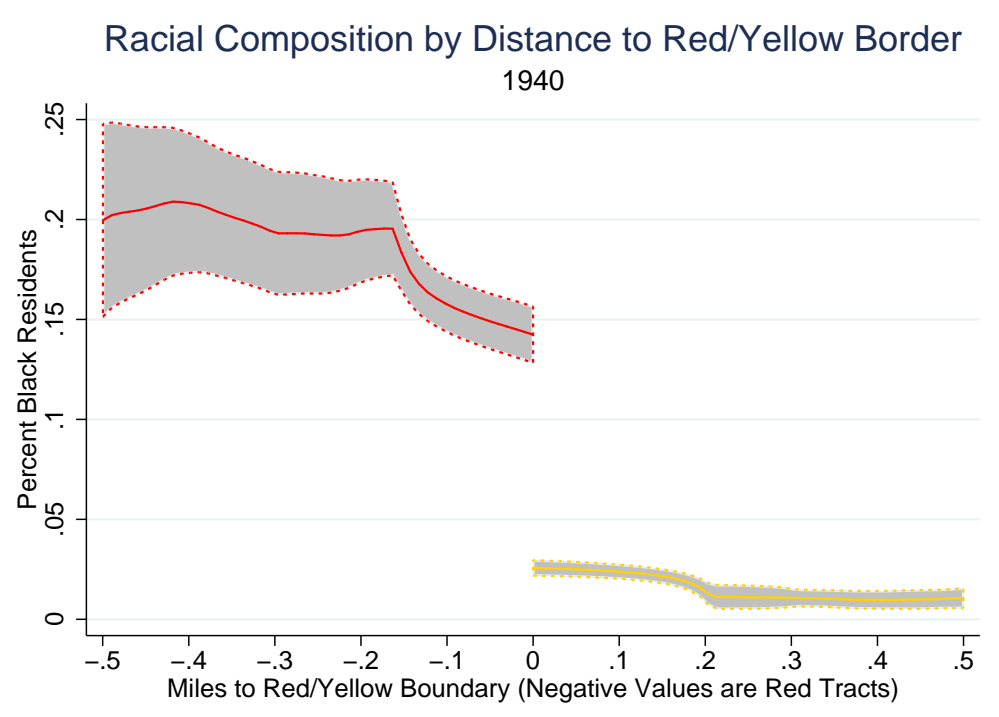

units, population density, the share of foreign born residents, labor force participation rate, and home vacancy rate. ${ }^{23}$ Moving farther from the boundary, tracts are much less similar. Sizable discontinuities in homeownership, median house value, and median years of school completed still exist at the HOLC boundary, with larger differences moving away.

The selection concerns are threefold: (1) The control and treatment groups are not observationally equivalent at the onset of the policy; (2) Redlined tracts were specifically selected against because they were already declining, and thus any differential changes after the fact could be attributed to a continuation of pre-trends rather than the policy; (3) the boundaries were drawn in a particularly forward-looking manner, whereby surveyors expected lower-rated neighborhoods to decline in the future, irrelevant of the policy. If this were the case, failing to account for the 'forward-looking boundaries' would result in upwardly biased estimates.

To combat the selection concerns in the raw data, my analysis focuses only on neighborhoods on the HOLC red-yellow boundary. I also control for tract level observables in 1940 and include both border segment and city-by-year fixed effects. Appendix Table 9.4 shows that controlling for tract-level covariates and border segment and city fixed effects can effectively account for differences in housing supply or population density in 1940. However, these controls cannot explain the small but significant differences in 1940 racial composition or rates of homeownership.

The difference-in-differences identifying assumption is one of parallel trends: absent the HOLC policy, differences between the pre and post period for the redlined D-graded neighborhoods would be the same as those in the yellow C-graded neighborhoods. This implies that absent the credit restrictive policies, the change in outcomes (like housing supply, population density, homeownership rate, and racial composition) for redlined areas would not have been different than the change in outcomes for the non-redlined (control) areas. While parallel trends cannot be tested directly, evidence of differential pre-trends is an indication the parallel trends

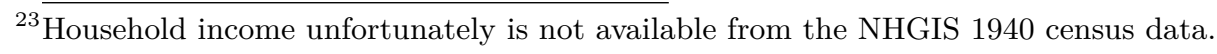


Figure 4: Initial Conditions at the Border, 1940 (raw data)
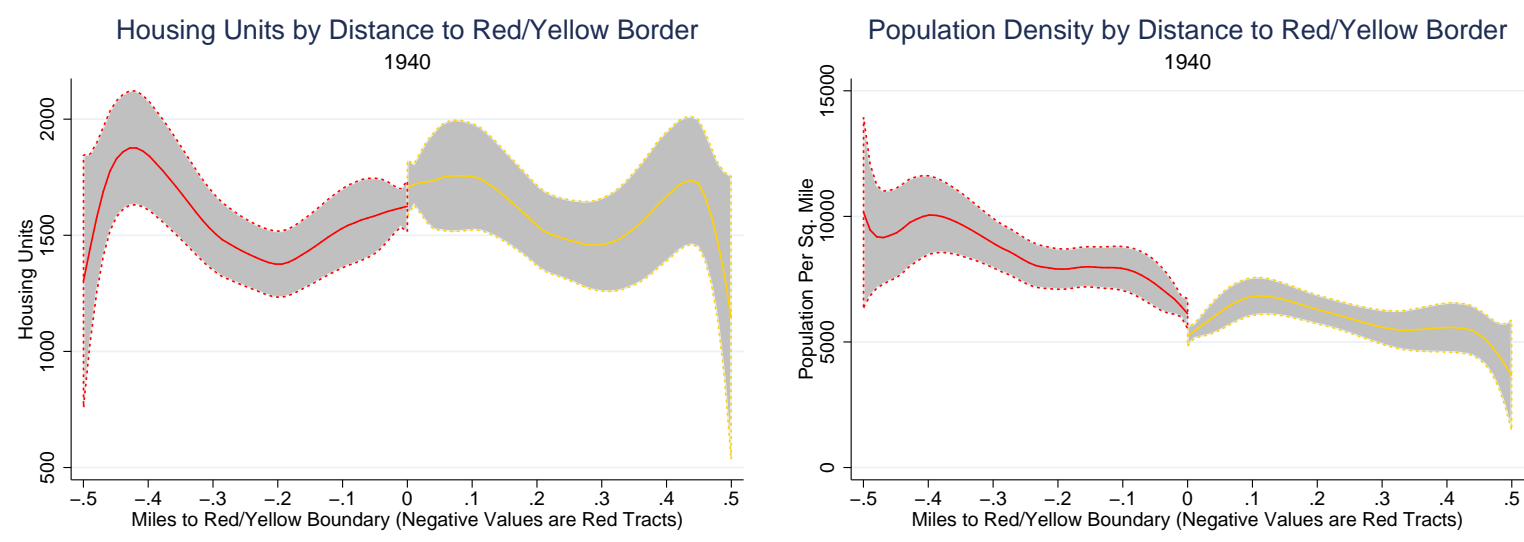

Homeownership Rate by Distance to Red/Yellow Border 1940
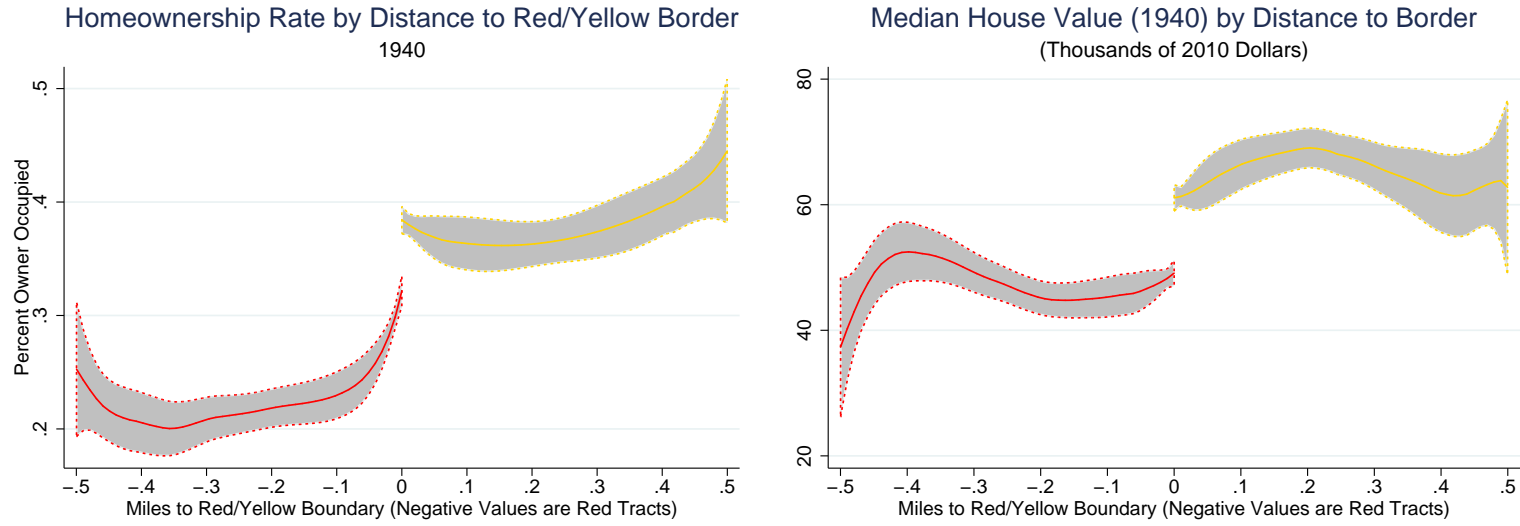

Foriegn-Born Residents by Distance to Red/Yellow Border 1940

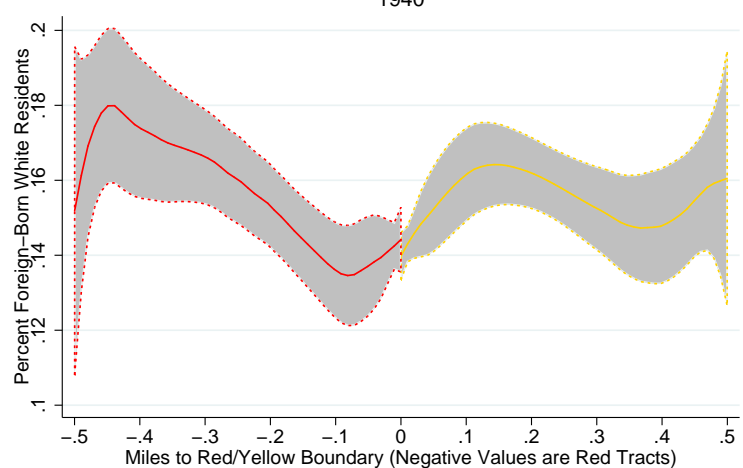

Male LFPR by Distance to Red/Yellow Border 1940
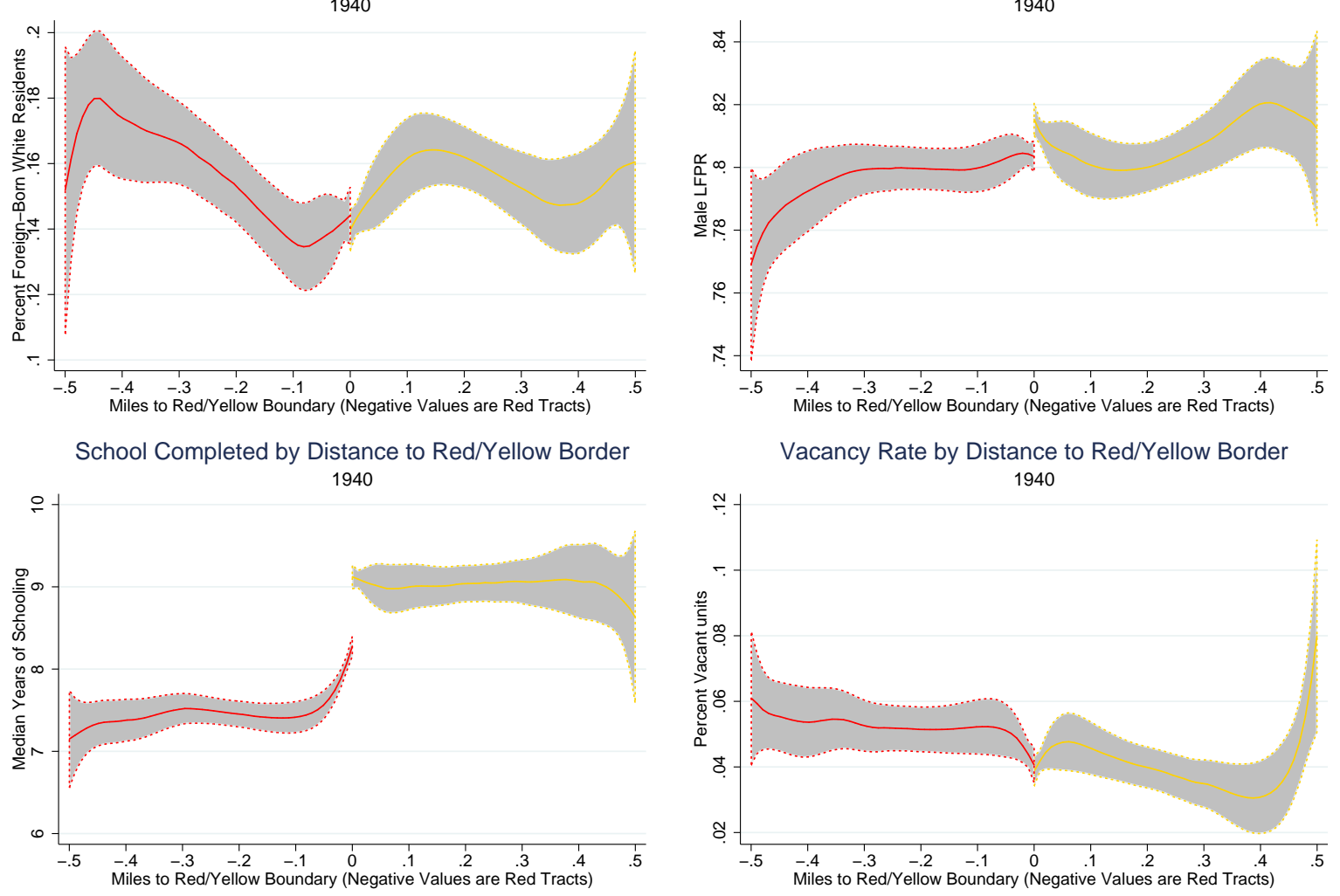
assumption might be violated. Nationwide census tract level data does not exist for 1930 and earlier, so I am unable to empirically test for pre-trends for the full sample.

Table 3 tests for differential pre-trends between adjacent red and yellow tracts for the 19 cities which have census tract data and a digitized HOLC map. The list of these cities can be found in Appendix Table 9.3. The coefficient of interest is the the difference-in-differences estimator ("Redlined X 1930"), which compares the differential trend between redlined and yellow-lined census tracts in 1930 relative to 1940 (the omitted reference group). The specifications control for border segment fixed effects and city-by-year fixed effects. Standard errors are clustered at the border segment level, rather than the city level (as they are in the main results specifications) because the 1930-1940 sub-panel contains only 19 cities.

The difference-in-differences coefficient shows no statistically significant changes in housing supply, population density, or homeownership rates between 1930 and 194024 Note the coefficient on redlined is always statistically significant, suggesting that over the 1930-1940 time period redlined border neighborhoods had 12 percent fewer housing units, 13 percent fewer people per square mile, 4 percentage more black residents, and 2 percent lower homeownership.

There is, however, a slight pre-trend in racial composition. The share of black residents (Table 3, column 3) increased differentially by about 2 percentage points in redlined tracts relative to adjacent yellow-lined neighborhoods between 1930 and 1940. Despite the statistical significance, the racial pre-trend is not particularly concerning for two reasons. First, the magnitudes are very small in absolute terms and are driven entirely by variation in the redlined side. As shown in Figure 3, on average, there were nearly no black residents on the yellow side of the border in 1940 25 Because the share of black residents in yellow border tracts was close to zero in both 1930 and 1940, any level change in the share of black residents in redlined tracts would produce a differential pre-trend. Pooling across the sample, the average tract was about 4.3 percent black in 1930 (not shown). Summing up the regression coefficients, redlined tracts went from about 7.5 percent black $(0.043-0.020+0.009+0.043)$ in 1930 to 8.6 percent black $(0.043+0.043)$ in 1940 . While statistically significant, it is not clear that such a change is economically meaningful. Second, if this were to violate the parallel trends assumption, one would expect the upward trend between 1930 and 1940 to continue and redlined border tracts would become more black after 1940. This is in fact the opposite of what we see. Between 1940 and 1970 (not shown), the share of black residents in these same sub-panel redlined tracts falls differentially by about 3 percentage points (not statistically significant) relative to adjacent yellow tracts. In the full sample, the share of black residents in redlined tracts falls differentially between 1940 to 1970 by about 0.8 percentage points (Table 5, column 3).

\footnotetext{
${ }^{24}$ The 1930 census has tract-level data on the number of occupied housing units, but not the total number of housing units, as I use throughout the rest of the paper. I compare the log of occupied housing units in 1930 and 1940

${ }^{25}$ The raw data (not shown) confirm that yellow-border tracts in the pre-trend sub-panel were only 1.6 percent black in 1930 and 1.7 percent black in 1940.
} 
Table 3: Testing for Differential Pre-Trends, 1930-1940

\begin{tabular}{lcccc}
\hline & $(1)$ & $(2)$ & $(3)$ & $(4)$ \\
& Log Occupied HUs & Log Pop/sqmi & Pct. Black & Pct. OwnerOcc \\
\hline Redlined X 1930 & -0.005 & 0.043 & $-0.020^{* * *}$ & 0.004 \\
& $(0.027)$ & $(0.032)$ & $(0.005)$ & $(0.006)$ \\
1930 & $0.479^{* * *}$ & 0.062 & $0.009^{*}$ & $0.340^{* * *}$ \\
& $(0.070)$ & $(0.070)$ & $(0.005)$ & $(0.029)$ \\
Redlined & $-0.120^{*}$ & $-0.130^{*}$ & $0.043^{* * *}$ & $-0.024^{* *}$ \\
& $(0.064)$ & $(0.071)$ & $(0.010)$ & $(0.010)$ \\
\hline Observations & 1638 & 2106 & 2043 & 1638 \\
$R^{2}$ & 0.219 & 0.288 & 0.130 & 0.422 \\
Sample & Border Tracts & Border Tracts & Border Tracts & Border Tracts \\
Mean & 7.07 & 9.6 & .05 & .36 \\
\hline All specifications include controls, border segment FE, and city-by-year FE & \\
Standard errors (in parentheses) are clustered at the border line segment level & \\
${ }^{*} p<.10,{ }^{* *} p<.05,{ }^{* * *} p<.01$ & &
\end{tabular}

The final major identification concern is that the parallel trends assumption does not hold due to confounding policies, events, or local political boundaries that would exacerbate differences between tracts of different colors. This could happen for several reasons. First, the HOLC boundaries could have been drawn in a particularly forward-looking manner. Even in the absence of differential pretrends, the prospect of 'forward-looking boundaries' (whereby the HOLC lines divided neighborhoods expected to thrive from those expected to decline) would upwardly bias the difference-in-differences estimates. One way in which boundaries may have been drawn in a forward-looking manner is if surveyors expected neighborhoods with more black residents and/or older housing to decline in the future. While my results are robust to controlling for initial housing characteristics and when the sample is limited to all-white neighborhoods, this may not be enough to fully assuage concerns regarding the anticipatory nature of the policy.

Second, highway or railroad construction (Baum-Snow, 2007; Brinkman and Lin, 2017), slum clearance policies, or riots may have occurred along or interacted with the credit redlining policy and/or the HOLC bounds I exploit. It is also possible that local political districts may have been drawn along the HOLC boundaries. And so depending on the efficacy of local political representatives, public good provision may have varied across redlined and yellow-lined neighborhoods after 1940 in ways I do not observe. I cannot control for such potential confounders due to data limitations. There is also the potential that unobserved policies or trends coincident with the repeal of redlining could overstate the effect of striking down discriminatory lending. If urban renewal projects and various place-based redevelopment projects were more likely to occur in once-redlined boundary neighborhoods, the effect sizes on redlining repeal will be biased upwards. 


\section{Estimation Strategy}

In order to best deal with selection issues and the fact that there are initial differences between red neighborhoods and yellow neighborhoods, I run a difference-in-differences comparing only tracts on either side of a common HOLC neighborhood polygon border segment. Visually, instead of including all tracts that are either majority yellow or majority red (see the map on the left below, for example), the border analysis includes in the sample only census tracts that fall directly on either side of an HOLC Red(D)-Yellow(C) boundary line. I focus chiefly on D and C

\section{Figure 5: Border Tract Focus, Baltimore}
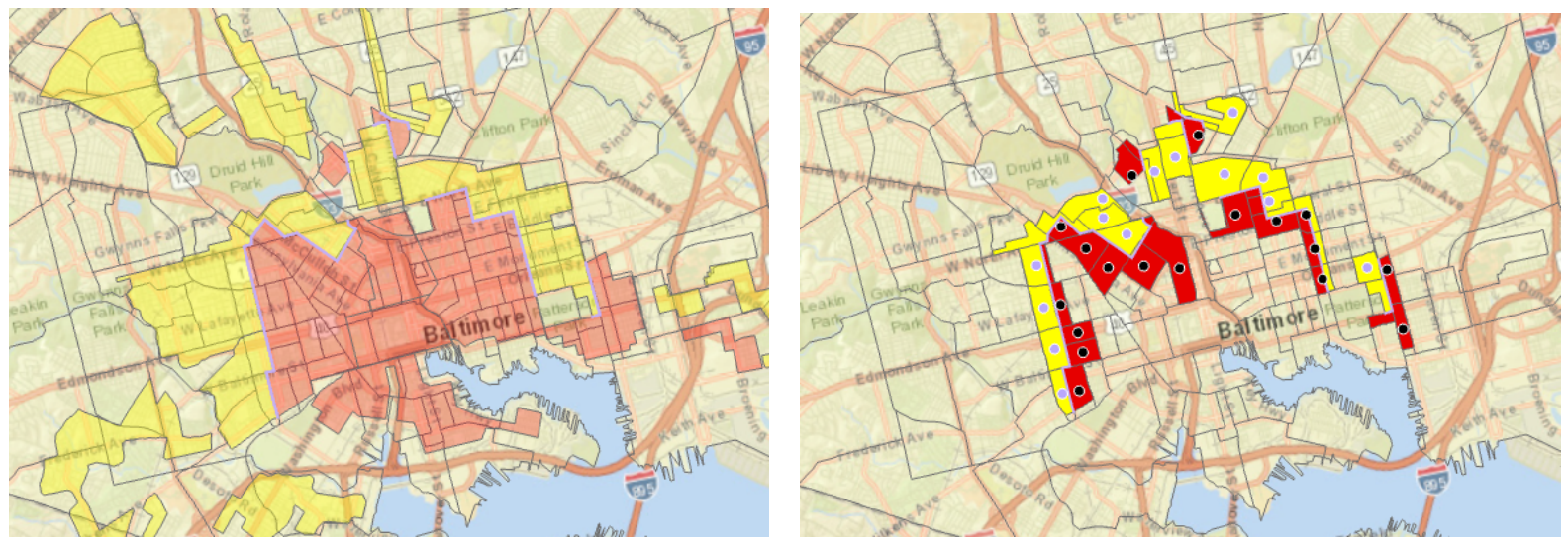

graded tracts for several reasons ${ }^{26}$ Most importantly, the motivation for studying the long-run impact of mortgage lending discrimination is to determine whether there were causal effects within areas where disinvestment was highest. Focusing only on tracts coded red and yellow captures the marginal effect of extreme lending discrimination relative to conservative lending practices ${ }^{27}$ They are also more similar than the others HOLC grades on observables, including lower homeownership, and, according to the HOLC guidelines, third and fourth grade areas should be serviced differently than first and second grade areas. Additionally, C and D graded tracts were both on similar downward trajectories, according to HOLC surveyors. Including all tract colors would not only certainly violate the parallel trends assumption, but it would also impose some unrealistic assumption about homogeneous treatment effects across residential security grades.

Estimating the effects of lending discrimination for only Red-Yellow border tracts presents a tradeoff between greater statistical power and cleaner measurement on one hand and better identification on the other. Of the 5,026 census tracts that received an HOLC grade of $\mathrm{C}$ or D in the sample, only 2,055 lie on or intersect a C-D border. Table 4 in Section 7 shows estimated effect size drops and standard errors increase moving from a sample of all red and yellow tracts to only those on the border. Focusing only on border neighborhoods may also magnify classical measurement error because census tract boundaries often do not line up with with neighborhood boundaries drawn by HOLC surveyors. Tracts in the treatment group could

\footnotetext{
${ }^{26}$ Analysis of A-B, B-C, and B-D borders can be found in the appendix.

${ }^{27}$ Also, looking back at summary statistics tables above, the vast majority of tracts were coded either red or yellow (over 70 percent).
} 
actually have portions that are in control areas (and vice versa) ${ }^{28}$ Because I do not observe lending behavior, I cannot determine the extent to which discriminatory practices spilled over into yellow-lined areas. The border tract analysis may be more sensitive to positive or negative spillover effects compared to using a wider geographic bandwidth.

\subsection{Estimating Equation}

The border analysis is estimated with the following equation:

$$
y_{i b c t}=\beta_{1}\left(D_{i b c} \times P_{t}\right)+\beta_{2} D_{i b c t=1940}+\beta_{3} P_{t}+\delta X_{i b c}+\alpha_{b}+\gamma_{t c}+\epsilon_{i c t}
$$

where $y$ is the outcome variable of interest for tract $i$ located along border $b$ in city $c$ at time $t$; $D_{i b c}$ is a dummy variable for whether tract $i$ is treated-that is whether it received a $D$ grade from the HOLC surveyors; $P_{t}$ is a dummy variable for the post-treatment period; $X_{i b c}$ are tractlevel covariates controlling for differences in initial conditions (as seen in Table 3); $\alpha_{b}$ is a time invariant HOLC border segment fixed effect; $\gamma_{t c}$ is a time-varying year-by-city fixed effect; and $\epsilon_{i b c t}$ is an error term. The specification includes only border tracts coded red and those colored yellow, so the control group in this analysis are yellow, or C-Graded, tracts. The difference-indifferences coefficient of interest is $\beta_{1}$, while $\beta_{2}$ captures the average difference between treated and untreated tracts, $\beta_{3}$ captures the time effect.

\subsection{Border Line Segment Fixed Effects}

Tracts are indexed by their main border $b$ in city $c$ at time $t$. The "main border" is defined as the longest red-yellow boundary line that intersects or overlaps the tract's own boundary. Because both treated and control tracts will share common main borders $b$, the border analysis must include both treatment and post dummies. This runs in contrast to a generalized difference-in-difference, as tract and time fixed effects are collinear with treatment and 'post', respectively. A tract is either treated or not, while a border is both treated and untreated by definition.

The border fixed effect $\alpha_{b}$ is in principle flexible across specifications. A border could be defined broadly as a HOLC polygon boundary or as narrowly as a HOLC polygon line segment combination. For example, a polygon boundary might be the long border found in the northwest corner of the Figure 5 Baltimore map on the left above. All boundary tracts closest to this polygon combination borderline would be grouped together. Instead I prefer the HOLC polygon line segment fixed effect, as it is more specific and localized. A line segment fixed effect groups together tracts on either side of a specific portion of the HOLC polygon combination boundary. For instance, the red-yellow HOLC polygon border in the northeast portion of the maps above is reproduced on the following page. Under a specification controlling only for polygon fixed effects, all these tracts would be grouped together, as they all share the common

\footnotetext{
${ }^{28}$ Recall that I define tracts as Redlined if their plurality HOLC color is red. The results are robust to alternate definitions of the treatment group, such as the grade of the tract's centroid point or a continuous treatment variable (percent redlined versus percent yellow-lined).
} 
Figure 6: Border Line Segment Focus

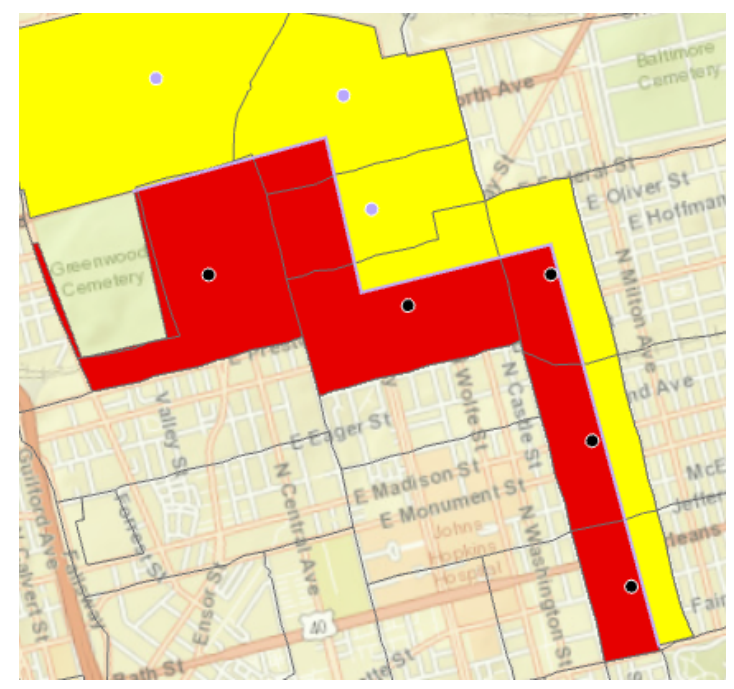

HOLC polygon boundary. HOLC polygon border line segment fixed effects instead group tracts on either side of the specific jagged edges of the larger boundary. In my robustness tests, I also test using neighborhood matched-pair fixed effects. In a matched pair setting, I find for each border tract whose centroid is in a red area the closest border tract whose centroid is in a yellow area. If multiple red tracts are closest to the same yellow tract, I match the red tract/yellow tract pairing whose distance is the smallest.

Including border segment and city-by-year fixed effects will in principle deal with some of the identification concerns about other policies or events confounding the effect of redlining. Cityby-year interacted fixed effects control for any citywide time-variant and invariant unobservables, such as such as political climate, citywide initiatives, citywide time-varying construction costs, etc. Additionally, the HOLC border segment fixed effects will control for any time-invariant unobservables occurring at the immediate points of neighborhood adjacency. These border segment fixed effects control for local geographic observables and unobservables not varying over time, such as location or topography. Yet, any unobservable time-variant, non-citywide intervention occurring only on one side of the border would bias the results. I cluster standard errors at the city level to control for the fact that tracts within the same city might be correlated in some unknown way.

\subsection{Outcomes and Measurement}

Housing is a building block of personal wealth and a hallmark of neighborhood desirability. Since historical microdata on loan approvals or household wealth do not exist, I study the long-run effects of redlining on neighborhoods, rather than individuals. Still, a large body of research tells us that neighborhood quality affects an individual's earnings, education choices, and intergenerational mobility (Chetty et al., 2014; Chetty et al., 2010; Chetty, Hendren, and Katz, 2016; Katz, King, and Liebman, 2001). One would expect credit restrictions to negatively influence neighborhood quality through both the supply and demand channels. For instance, with banks reluctant to supply credit and government unwilling insure mortgages, real estate 
developers would prefer to build new homes elsewhere; unable to secure financing for even a deteriorating home, families would prefer to reside in non-redlined neighborhoods.

The four outcome variables of interest are tract-level housing supply (i.e. total number of housing units), the homeownership rate, population density, and the percent of black residents. I focus on these variables for several reasons. The supply of housing is a key indication of which areas real estate developers viewed as a safe investment and which areas were seen as more risky. Developers should build on plots located in less-risky (Grade C) land and neither construct new homes nor repair existing ones located on plots in redlined areas. Another reason for such behavior might be that developers would not construct new homes in areas where the HOLC and FHA would not underwrite loans. Creating this market reaction was precisely the goal of the HOLC and its surveyors. Exploring the changes in housing supply will help determine if the HOLC security maps actually affected behavior within the real estate industry.

Similarly, tracking the changes in homeownership between adjacent neighborhoods over time is also an indication of the availability of credit. Historical mortgage or credit data are not available at finer levels of geography, but the share of homes that are owner occupied should correspond to the supply of credit. Population density is an indicator of the concentration of economic activity and the density of housing; and tracking the evolution of density at such a fine geographic level illustrates the general desirability of the location.

Population and race measures are especially important in considering how redlining interacted with the "flight" of white residents from urban to suburban areas throughout the post-War period. Examining border tracts' share of black residents measures the level of racial segregation. Since HOLC credit ratings were chiefly determined by racial composition in 1940, tracking the percent of black residents provides insight on how redlining preserved or exacerbated existing segregation and whether the CRA simultaneously erased both HOLC grade lines and longstanding neighborhood racial boundaries.

Because I am interested in both the long-run (30-year) effects of HOLC redlining and whether trends are persistent after redlining became illegal, I run sets of analyses using two different pre and post periods. For the 30-year analysis, the pre-treatment period is 1940 and the posttreatment period is 1970. For the full period redlining reversal analysis, the pre-treatment period is 1940 to 1970, and the post-treatment period is 1980 to 2010. In my results for the full period analysis, I present figures showing the difference-in-differences regression predicted values for both treatment and control tracts for years 1940, 1970, 1980, 1990, 2000, and 2010. In this way, we can trace over time the evolution of housing supply, population, racial composition, and homeownership rates across borders over time. 


\section{$7 \quad$ Difference-In-Differences Results}

\subsection{Effects of Redlining: 1940-1970}

Table 4 below presents results for the long-run effects of HOLC redlining (from 1940 to 1970) on the stock of housing. Column 1 is a naive generalized difference-in-differences estimate using the full sample of red and yellow tracts and tract level fixed effects. (Note that all specifications in this table also include city-by-year interacted fixed effects and cluster standard errors at the city level). We see that on average redlined tracts saw a nearly 700 housing unit (37 percent, relative to the mean total housing units) decrease relative to yellow-graded tracts between the introduction of the HOLC maps in 1940 and 1970. Column 2 limits the sample to tracts within 0.5 miles of a HOLC red-yellow boundary and includes controls for differences in tracts' initial conditions. This specification also uses border segment fixed effects. We see that narrowing the sample to tracts within half a mile only reduces the point estimate by about 80 housing units (by 4-5 percent), from 695 to 615 fewer homes in redlined areas in 1970. Note that the point estimate on post-1940 is large and significant, meaning there are significantly more homes in these areas in general in 1970 (i.e. the rate of home construction was extremely high in the post-war period). Also notice that the coefficient on Redlined is statistically significant, meaning the controls and fixed effects are unable to explain the baseline differences in housing supply between red and yellow tracts within 0.5 miles of the boundary.

Moving to column 3, we see that limiting the sample to border tracts alone reduces the coefficient of interest (Post40 X Redlined) substantially, but the point estimate remains large and statistically significant. Column 4 (the preferred specification) includes tract level covariates as well. Interpreting the difference-in-differences coefficient, redlined border tracts in 1970 had differentially 470 fewer housing units than adjacent tracts on the yellow-side of the border, a difference of about 23 percent. Summing up the first three coefficients $\left(\beta_{1}+\beta_{2}+\beta_{3}\right.$ in the estimating equation), there was effectively no change in the supply of housing in redlined border tracts between 1940 and 1970, compared to a large increase in the housing supply in neighborhoods on the higher graded side of the border. Such a story of further borne out by evidence in Figure 7.

As a simple robustness exercise in the introductory table, column 5 controls for tract matched pair fixed effects, where red border tracts are paired with their closest yellow neighbor 29 Notice the number of observations drops from 4110 to 1830. The point estimate on the difference-indifferences coefficient is negative and statistically significant at -173 housing units (about a 9 percent decrease). Taken together, these results imply that while redlining was legal, home building and/or housing durability in yellow graded areas far exceeded that in redlined areas. This finding is robust to several types of border fixed effects.

Table 5 repeats the preferred specification (column 4 of Table 4) for the log housing supply, log population density, percent of black residents, and percent of owner occupied homes (home-

\footnotetext{
${ }^{29} \mathrm{~A}$ full set of robustness matched pair FE regressions can be found in the appendix.
} 
Table 4: Effect of Redlining on Housing Stock, 1940-1970

\begin{tabular}{|c|c|c|c|c|c|}
\hline & $\begin{array}{c}(1) \\
\text { Total Units }\end{array}$ & $\begin{array}{c}(2) \\
\text { Total Units }\end{array}$ & $\begin{array}{c}(3) \\
\text { Total Units }\end{array}$ & $\begin{array}{c}(4) \\
\text { Total Units }\end{array}$ & $\begin{array}{c}(5) \\
\text { Total Units }\end{array}$ \\
\hline Post40 X Redlined & $\begin{array}{c}-695.458^{* * *} \\
(117.051)\end{array}$ & $\begin{array}{c}-615.778^{* * *} \\
(118.191)\end{array}$ & $\begin{array}{c}-470.737^{* * *} \\
(159.885)\end{array}$ & $\begin{array}{c}-470.737^{* * *} \\
(160.063)\end{array}$ & $\begin{array}{c}-173.607^{* *} \\
(80.822)\end{array}$ \\
\hline Post-1940 & $\begin{array}{c}685.465^{* * *} \\
(25.446)\end{array}$ & $\begin{array}{c}668.143^{* * *} \\
(25.694)\end{array}$ & $\begin{array}{c}409.009^{* * *} \\
(43.605)\end{array}$ & $\begin{array}{c}409.009^{* * *} \\
(43.653)\end{array}$ & $\begin{array}{c}24.167 \\
(53.882)\end{array}$ \\
\hline Redlined & & $\begin{array}{c}178.447^{* *} \\
(67.295)\end{array}$ & $\begin{array}{l}-66.106 \\
(86.120)\end{array}$ & $\begin{array}{c}95.720 \\
(98.769)\end{array}$ & $\begin{array}{l}-24.658 \\
(56.972)\end{array}$ \\
\hline Distance to Border & & $\begin{array}{c}26.664 \\
(90.181)\end{array}$ & & & \\
\hline Tract Area & & $\begin{array}{c}185.805^{* *} \\
(72.760)\end{array}$ & & $\begin{array}{c}132.542^{\text {*** }} \\
(35.789)\end{array}$ & $\begin{array}{c}1355.975^{* * *} \\
(203.710)\end{array}$ \\
\hline Pct.Blk in ' 40 & & $\begin{array}{c}634.298^{* * *} \\
(119.846)\end{array}$ & & $\begin{array}{c}845.184^{* * *} \\
(220.623)\end{array}$ & $\begin{array}{l}456.860^{* *} \\
(198.403)\end{array}$ \\
\hline LFPR in ' 40 & & $\begin{array}{c}914.418^{* * *} \\
(287.034)\end{array}$ & & $\begin{array}{c}595.646 \\
(837.463)\end{array}$ & $\begin{array}{c}1938.922^{*} \\
(1057.221)\end{array}$ \\
\hline Pct.Foreign in ' 40 & & $\begin{array}{c}383.795 \\
(344.154)\end{array}$ & & $\begin{array}{l}1328.978 \\
(864.923)\end{array}$ & $\begin{array}{c}667.104 \\
(1009.619)\end{array}$ \\
\hline Pct.Disrepair in ' 40 & & $\begin{array}{c}-487.997^{* * *} \\
(133.550)\end{array}$ & & $\begin{array}{l}-549.122 \\
(377.404)\end{array}$ & $\begin{array}{l}-497.049 \\
(464.963)\end{array}$ \\
\hline Pct.Radio in ' 40 & & $\begin{array}{l}-580.735^{*} \\
(320.789)\end{array}$ & & $\begin{array}{l}-908.949^{*} \\
(538.695)\end{array}$ & $\begin{array}{c}-451.660 \\
(1005.247)\end{array}$ \\
\hline Pct.Heating in $40^{\prime}$ & & $\begin{array}{c}8.190 \\
(194.358)\end{array}$ & & $\begin{array}{l}-127.140 \\
(408.363)\end{array}$ & $\begin{array}{c}2.079 \\
(412.542)\end{array}$ \\
\hline Pct.Fridge in ' 40 & & $\begin{array}{c}995.168^{* * *} \\
(351.214)\end{array}$ & & $\begin{array}{c}1342.732^{* * *} \\
(420.940)\end{array}$ & $\begin{array}{l}946.345^{*} \\
(553.253)\end{array}$ \\
\hline Schooling in ' 40 & & $\begin{array}{c}103.634^{* * *} \\
(19.241)\end{array}$ & & $\begin{array}{c}112.827^{* *} \\
(42.584)\end{array}$ & $\begin{array}{c}34.434 \\
(31.640)\end{array}$ \\
\hline Observations & 10052 & 8630 & 4110 & 4110 & 1830 \\
\hline$R^{2}$ & 0.217 & 0.211 & 0.161 & 0.222 & 0.301 \\
\hline Sample & All Red \& Yellow & 0.5 Mile Radius & Border Only & Border Only & Nearest Match \\
\hline FE & Tract & Border Segment & Border Segment & Border Segment & Matched Pair \\
\hline Mean DV & 1897.09 & 1904.8 & 2032.07 & 2032.07 & 1893.74 \\
\hline
\end{tabular}


ownership rate). Column 1 replicates the result (though this time in logs) of Table 4 . We see that redlining is associated with about a 20 percent decrease in the housing stock relative to control neighborhoods located on the yellow side of the HOLC boundary. Similarly, redlining caused a 22 percent decline in population density (column 2), which is amounts to about 2,750 people per square mile, on average. Between 1940 and 1970, redlining had no differential effect on racial composition or neighborhoods' homeownership rate-though notice that the coefficients on the treatment variable are significant in both columns 3 and 4 . This suggests that throughout the 1940-70 time period, redlined border neighborhoods have significantly more black residents and a lower homeownership rate than those on the other side of the boundary. Existing disparities in segregation and home ownership continued throughout the redlining regime.

Table 5: Effects of Redlining, 1940-1970

\begin{tabular}{lcccc}
\hline & $(1)$ & $(2)$ & $(3)$ & $(4)$ \\
& Log Total Units & Log Pop/sqmi & Pct. Black & Pct. OwnerOcc \\
\hline Post40 X Redlined & $-0.198^{* * *}$ & $-0.220^{* * *}$ & -0.008 & 0.006 \\
& $(0.051)$ & $(0.045)$ & $(0.016)$ & $(0.005)$ \\
Post-1940 & $0.159^{* * *}$ & $-0.134^{* * *}$ & $0.205^{* * *}$ & $0.081^{* * *}$ \\
& $(0.014)$ & $(0.012)$ & $(0.004)$ & $(0.001)$ \\
Redlined & 0.043 & 0.046 & $0.036^{* * *}$ & $-0.034^{* * *}$ \\
& $(0.058)$ & $(0.065)$ & $(0.011)$ & $(0.012)$ \\
\hline Observations & 4106 & 4110 & 4108 & 4101 \\
$R^{2}$ & 0.180 & 0.217 & 0.373 & 0.279 \\
Sample & Border Only & Border Only & Border Only & Border Only \\
Mean & 7.26 & 9.38 & .19 & .38 \\
\hline Standard errors in parentheses & & & \\
All specifications include tract-level controls, border segment FE, city-by-year FE and cluster SEs at city level \\
${ }^{*} p<.10,{ }^{* *} p<.05,{ }^{* * *} p<.01$ & & &
\end{tabular}

\subsection{Effects of Repeal: 1977-2010}

Figure 7 presents graphical representations of the difference-in-differences regressions for the full sample period of 1940 through 2010. The lines are predicted means from the border fixed effect regressions (using the preferred specification), so the estimates compare predicted average differences between adjacent neighborhoods on either side of the same Red-Yellow HOLC boundary line segment 30 The vertical red line in 1977 represents the passage of the Community Reinvestment Act, which formally outlawed redlining. Examining the top left panel between 1940 and 1970, we see that there was no new housing (on net) in redlined areas compared to large gains in the housing stock (about 16 percent) for yellow neighborhoods (the black line, for visual ease) on the other side of the HOLC border.

In the repeal period represented by census years 1980 through 2010, the housing stock on both sides of the boundary slowly depreciates. Over this time, the spatial discontinuity in the housing stock between adjacent red and yellow tracts actually widens by about 17 percent (see Appendix table 9.5). Despite no net home construction on either side of the boundary, the decline is more dramatic in redlined areas, likely due to older, lower-quality pre-War housing.

\footnotetext{
${ }^{30}$ See Appendix table 9.6 for the coefficients.
} 
On average, there was no new building, on net, in these areas during the 1940-2010 sample period. During the post-war construction boom, developers may have been steered to build on the higher rated side of the Red-Yellow boundary. This is evidence that the HOLC grading and appraisal system actually mattered for the real estate industry. After redlining was outlawed, the discontinuities that arose between 1940 and 1970 persisted.

The top right panel shows the monotonic decline in population density in both red and yellow border tracts. The decline is more dramatic in redlined neighborhoods, but it does not appear that people are simply migrating to the higher graded side of the HOLC boundary. Instead, as the upcoming section will show, these declines are driven by the out-migration of white residents in both red and yellow border neighborhoods; this white out-migration is not surprisingly more pronounced in redlined neighborhoods. Like the housing stock figure, there are no changes in the population density trends after redlining was made illegal. The effects of redlining on housing supply and population density are clear: proximate neighborhoods with similar features diverged wildly between 1940 and 1970; and the repeal of redlining had no effect on this spatial discontinuity.

\section{Figure 7: Effects of Redlining and Repeal, 1940-2010}
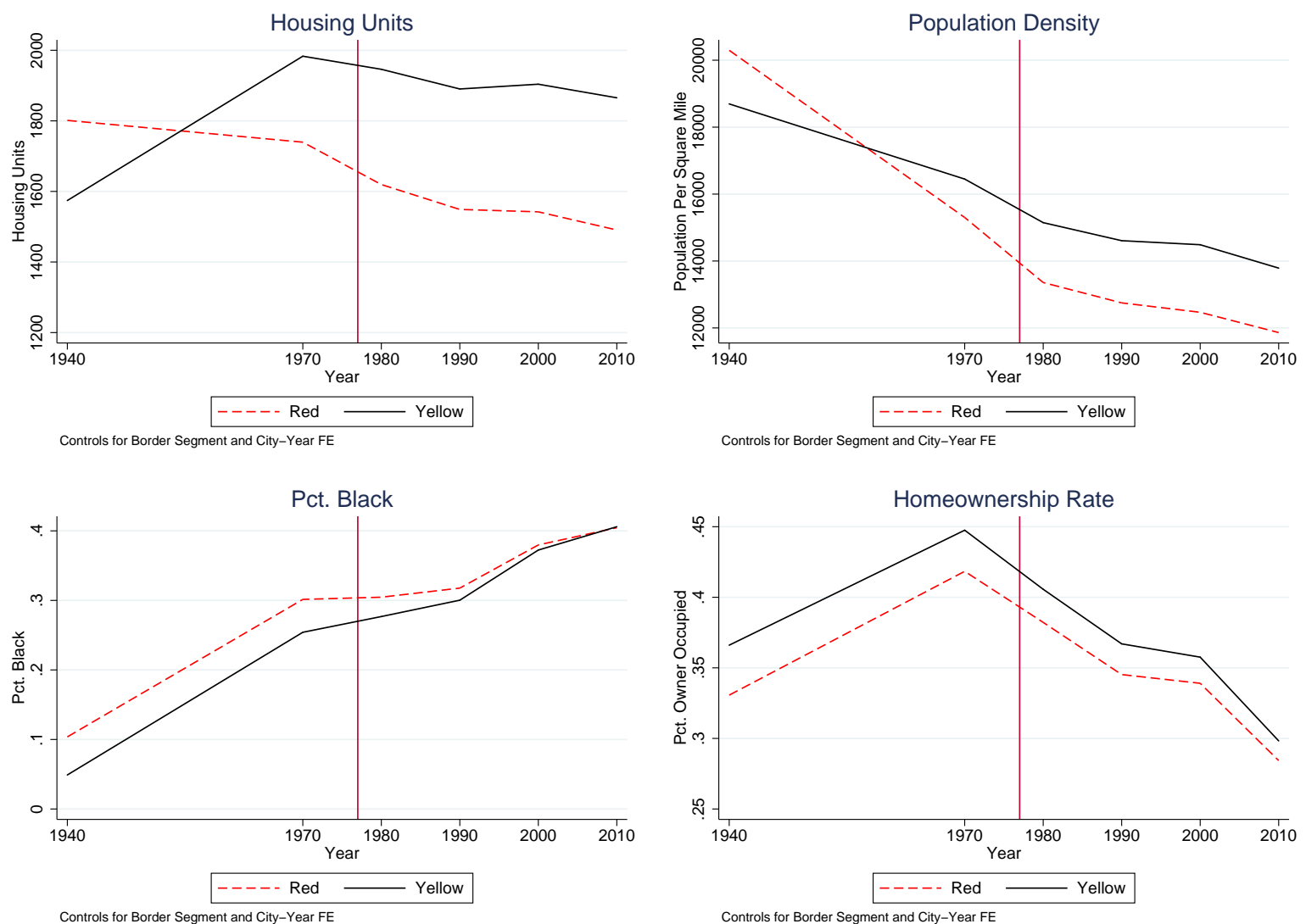

The figures for the share of black residents and homeownership rate tell a somewhat different story. The system of redlining preserved the spatial discontinuities in race and homeownership from 1940 to 1970. The repeal of redlining practices actually led to some convergence, as the 
gap in the black population share decreased by about 5 percentage points between 1970 and 2010. The gap in homeownership declined by about 1.5 percentage points over this same time period. Importantly, these bottom two panels in Figure 7 also illustrate the secular trend of a higher black population share and lower rates of homeownership rates in both red and yellow border tracts after redlining was outlawed.

Comparing these competing post-redlining stories of persistence (in the case of housing supply and density) and convergence (in the case of racial composition and homeownership), it seems that some trends are more easily reversed by anti-discrimination legislation than others. Fighting segregation and boosting homeownership were two primary goals of the Fair Housing Act, the HMDA, and the CRA. Neighborhood reinvestment and new home construction are much taller tasks-and ones that rely much more heavily on market demand and private sector action.

\subsection{Heterogeneous Effects}

Because the HOLC grades were drawn along pre-existing racial lines and because there was already institutionalized segregation and racism throughout the real estate industry, education system, and labor market, there is a major concern that the previous results are either due totally to structural racism or at least biased upwards due to racism unrelated to HOLC redlining. I confront this concern in two ways. First, I present a triple difference interacting the difference-in-differences estimator with the tract's black population share in 1940. This triple difference specification will help to decompose the total effect of redlining into the effect of the HOLC credit grading and the effect of other forms of structural discrimination. Second, I show in the following section that the main results hold even for borders with homogeneously white neighborhoods on either side in 1940.

Given the role of race in the selection of HOLC boundaries, one would certainly expect that neighborhoods with a higher proportion of black residents would be subject to even harsher lending discrimination and less investment. Yet it is unclear ex ante whether the neighborhoods would have fared just as poorly had the formal redlining policy never been enacted. The triple difference specification attempts to disentangle the effects of HOLC redlining from the more general pervasive racism of the period. The triple difference lets the treatment effect coefficient (Post-1940 X Relined) vary by a tract's initial share of black residents. The rationale for this is that perhaps effects are stronger for, or only driven by, neighborhoods with a high proportion of black residents in 1940. If the triple difference specification totally changes the coefficient on the difference-in-differences parameter, this is evidence that broader forces of segregation and racism were confounding the results previously attributed to HOLC redlining. The results in Appendix table 9.7 show this is not the case. Alternatively, if the coefficient on the triple difference is significant, this is evidence of a heterogeneous effect on neighborhoods with a higher initial share of black residents.

To determine how the difference-in-differences estimate varies by a neighborhood's 1940 
racial composition, I first discretize the tract's initial share of black residents into four buckets (less than 1 percent black, 1 to 10 percent, 10 to 25 percent, and greater than 25 percent). I then interact these indicator variables with the difference-in-differences estimator (and I also interact with the 'Post' and 'Redlined' indicators), creating a difference-in-difference-in-differences, or triple-difference estimate.

The triple-difference regression results can be found in Appendix 9.7. Table 9.7a shows the addition of the triple-difference term does not alter the difference-in-differences coefficient (Post40 X Redlined), which suggests a neighborhood's share of black residents is not driving the main results 31 The triple-difference coefficients in columns 1 and 2 indicate that the effect of redlining on total housing units and population density did not vary significantly by a tract's initial share of black residents. Though the triple-difference coefficients are large, they are not precisely estimated and do not vary systemically. Interestingly, column 3 shows that redlined tracts that were greater than 25 percent black in 1940 saw large differential declines (5 percentage points) in homeownership rates relative to redlined tracts that were less than 1 percent black in 1940 .

Appendix table 9.7.b presents the triple difference results for the post-repeal period. Again, including a triple difference does not alter the point estimates on the difference-in-differences coefficients ${ }^{32}$ The interactions here show redlined tracts that had higher shares of black residents in 1940 were differentially worse off in the repeal period. Compared to redlined tracts that were less than 1 percent black in 1940, the housing stock of redlined tracts that were over 25 percent black in 1940 fell by an additional 22 percent in the post-repeal period (this is in addition to the differential decline of 10 percent relative to neighboring yellow-graded areas). Redlined tracts with higher initial shares of black residents also saw differential (but not statistically significant) declines in homeownership. The gains in homeownership after 1977 were highly concentrated in redlined neighborhoods that were more white in 1940.

Because nearly all historically-black neighborhoods were labeled an extreme credit risk, the connection between redlining and race cannot be overstated. But although racial composition played a major role in determining whether a tract was redlined, I find racial discrimination and neighborhood segregation alone cannot explain the persistent housing and population trends along the HOLC redlining boundaries. Robustness exercises using an all-white subsample in the following section re-affirm this. The triple-difference exercise, however, also provides directional but imprecise evidence that neighborhoods with highest initial share of black residents were most adversely and persistently affected.

\footnotetext{
${ }^{31} \overline{\text { Compare the coefficients here of }-0.143,-0.169}$, and 0.004 to $-0.198,-0.22$, and 0.006 in the baseline specifications (First row of Table 4 ).

${ }^{32}$ Compare $-0.105,-0.127$, and 0.09 to $-0.171,-0.19$, and 0.13 in row 1 of Appendix table 9.5
} 


\subsection{Robustness}

The previous section showed the main results on housing supply, population density, and homeownership are not explained by pre-existing patterns of segregation or confounded by other forms of racial discrimination along the HOLC boundary lines. Despite the policy's disproportionate impact on black communities, I estimate redlining affected historically-white neighborhoods at a similar magnitude (albeit historically-white neighborhoods were marked for redlining at a far lower rate). In other words, the results hold even for red-yellow borders with homogeneously white neighborhoods on either side in 1940.

Table 6 below compares the effect sizes using the baseline sample (columns 1, 3, and 5) to their analogues using a limited sample of bordering neighborhoods that were homogeneously white in 1940. While the sample size shrinks by about 80 percent, the difference-in-difference magnitudes are quite robust. Redlining was associated with a differential decline in the housing supply of 14 percent, compared to 20 percent in the baseline sample. Effect sizes between the full and all-white sample are almost identical for the population density and homeownership rate outcomes.

Table 6: Redlining in Initially All-White Neighborhoods, 1940-1970

\begin{tabular}{|c|c|c|c|c|c|c|}
\hline & \multicolumn{2}{|c|}{ Log Total Units } & \multicolumn{2}{|c|}{ Log Pop/sqmi } & \multicolumn{2}{|c|}{ Pct. OwnerOcc } \\
\hline & (1) & $(2)$ & (3) & (4) & (5) & $(6)$ \\
\hline & All Borders & All-White Borders & All Borders & All-White Borders & All Borders & All-White Borders \\
\hline \multirow[t]{2}{*}{ Post40 X Redlined } & $-0.198^{* * *}$ & $-0.138^{*}$ & $-0.220^{* * *}$ & $-0.221^{*}$ & 0.006 & -0.005 \\
\hline & $(0.051)$ & $(0.076)$ & $(0.045)$ & $(0.119)$ & $(0.005)$ & $(0.011)$ \\
\hline \multirow[t]{2}{*}{ Post-1940 } & $0.159^{* * *}$ & $2.958^{* * *}$ & $-0.134^{* * *}$ & $2.636^{* * *}$ & $0.081^{* * *}$ & $-0.188^{* * *}$ \\
\hline & $(0.014)$ & $(0.076)$ & $(0.012)$ & $(0.119)$ & $(0.001)$ & $(0.011)$ \\
\hline \multirow[t]{2}{*}{ Redlined } & 0.043 & $-0.199^{*}$ & 0.046 & -0.139 & $-0.034^{* * *}$ & -0.034 \\
\hline & $(0.058)$ & $(0.112)$ & $(0.065)$ & $(0.099)$ & $(0.012)$ & $(0.027)$ \\
\hline Observations & 4106 & 828 & 4110 & 832 & 4101 & 824 \\
\hline$R^{2}$ & 0.180 & 0.284 & 0.217 & 0.323 & 0.279 & 0.405 \\
\hline Mean & 7.26 & 6.9 & 9.38 & 9.19 & .38 & .45 \\
\hline
\end{tabular}

Figure 8 compares the baseline results (left panels, for reference) to a sample including only neighborhoods that had zero black residents in 1940 (right panels). In principle, these neighborhoods must have received their HOLC rating for reasons other than the racial makeup of the residents. Between 1940 and 1970, the all-white C and D graded tracts both saw an increase in their housing supply, though the increase was larger in $\mathrm{C}$ graded areas. In the post-redlining period, the housing stock continues to increase and then drops dramatically for both red and yellow tracts; the difference between the ratings remains but converges somewhat by 2010. The regression results of Table 6 column 1 and 2 mask these divergent fortunes between the average redlined area and an all-white redlined neighborhood. To be sure, redlining had an adverse effect on the construction of new housing units. For the average border tract, this effect is driven by large increases in housing in yellow-lined areas compared with no new building, on net, in redlined areas between 1940 and 1970. However, among border tracts with no black residents in 1940 (top right panel of Figure 8), redlining's negative differential impact on construction 
is simply driven by disproportionately more building on the positively-selected (yellow graded) side of the HOLC boundary.

Figure 8: Robustness Exercise - All White Border Tracts, 1940-2010 All Red-Yellow Border Tracts (L) vs Border Tracts With No Black Residents in 1940 (R)
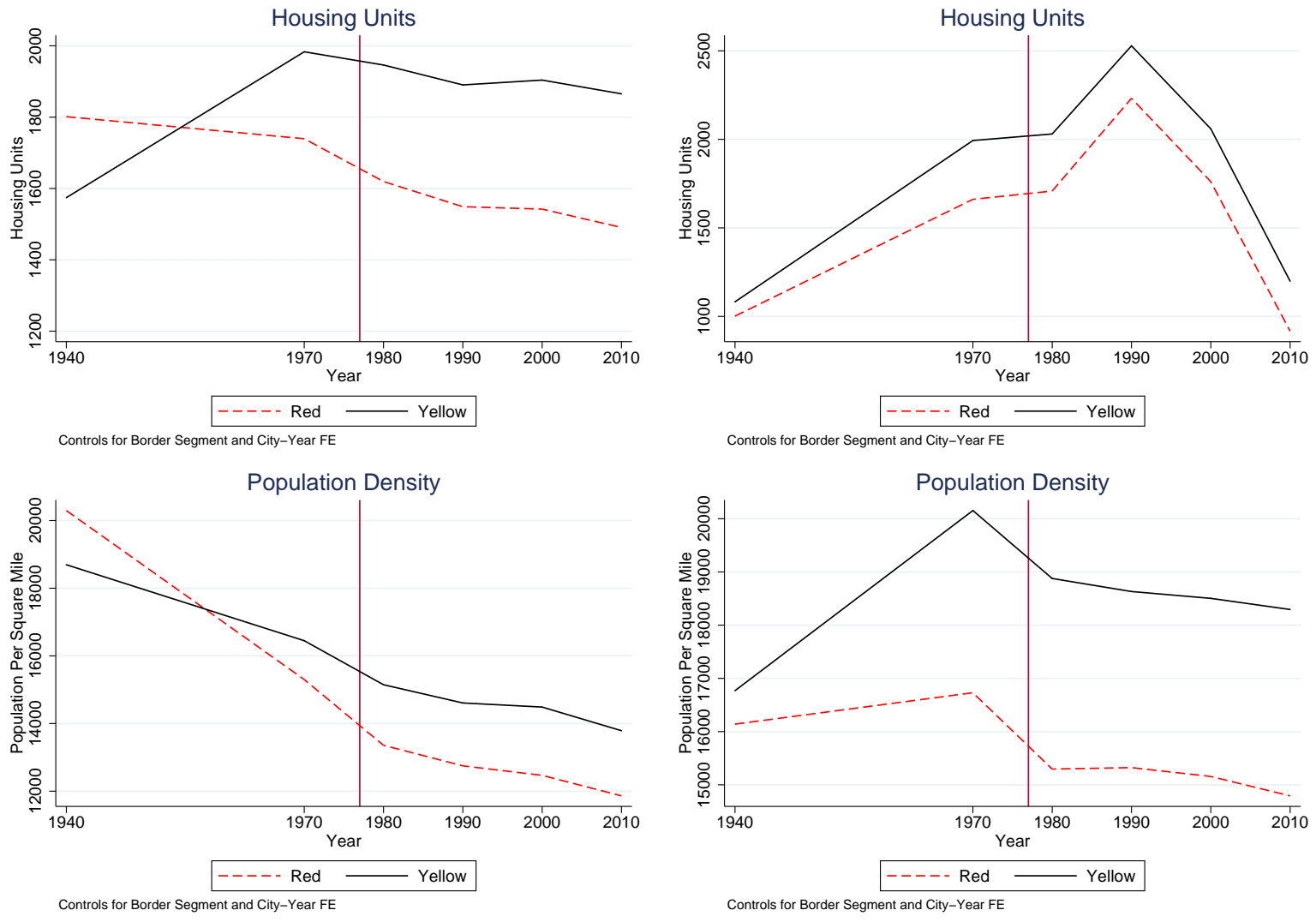

The bottom two panels show the results for population density. Over the course of the redlining period, population density in the homogeneously white adjacent red and yellow tracts diverged significantly. In the all-white sample, redlining was associated with a 22 percent decline in population density between 1940 and 1970; this magnitude is identical in the full sample. Like in the main results, this discontinuity persists post-repeal-and at a much larger magnitude.

Appendices 9.9 through 9.12 include a battery of other robustness and sensitivity checks. To test whether the results hold at a finer scale, I compare my baseline results to specifications using census tract matched-pair fixed effects (Appendix 9.9). The results are robust, though point estimates on housing supply are lower. There are slight power concerns, as the matchedpair specifications discard half the observations. Another potential concern is that the results could be sensitive to my redlining assignment rule (Recall, I assign a tract to treatment or control based on its plurality HOLC grade). Appendix 9.10 compares tracts that are at least $75 \%$ redlined versus tracts that are at least $75 \%$ yellow-lined. Again, the results do not change when treatment is less fuzzy, suggesting spillover effects in the main sample are not a major concern. I also confirm that trends in border tracts are rather representative of all redlined and yellow-lined tracts (Appendix 9.11). Finally, I repeat the baseline boundary analyses for other HOLC border combinations to test whether the HOLC lending guidelines bind for other 
residential security grades (Appendix 9.12). I do not find consistent patterns across other grade combinations, and no other combinations resemble my main results comparing adjacent red and yellow tracts. This suggests there was something unique to how the red-yellow assignment influenced real estate development and neighborhood desirability.

\section{Conclusion}

As part of a New Deal initiative to minimize the federal government's exposure to systemic mortgage foreclosure risk, the HOLC-a government sponsored enterprise-and local real estate professionals created incredibly detailed credit rating maps for each neighborhood every major American city. Using newly geo-rectified versions of the HOLC maps in over 50 cities, I formally document-both across and within cities-that surveyors targeted neighborhoods with even a small number of black residents; the HOLC disproportionately but not exclusively assigned those census tracts the most restrictive credit rating. In my full sample of cities, nearly 90 percent of African Americans in 1940 lived in a neighborhood marked for credit redlining by the HOLC.

I then use a difference-in-differences approach to trace out the evolution of housing and economic outcomes for geographically proximate census tracts located on either side of over 1,000 HOLC redlining borders. I estimate that between 1940 (the final year of the HOLC neighborhood survey program) and 1970 (several years before redlining was outlawed) neighborhoods on the credit-favored side of the boundary saw a large (16 percent) increase in the housing supply while adjacent redlined tracts experienced no new building on net. Similarly, redlining was associated with large (22 percent) differential declines in population. Cross-border gaps in homeownership and racial composition did not change differentially from their 1940 baseline though.

After discriminatory lending practices were made illegal, I find small but statistically significant evidence of convergence in racial segregation and homeownership across the HOLC redline boundaries. This provides weakly suggestive evidence that fair housing/anti-discrimination legislation helped reverse some of the negative effects of redlining, perhaps through increasing access to credit and strengthening legal protections for borrowers. On the other hand, large discontinuities in housing supply and population density persist at the redlining borders nearly 40 years after the discriminatory lending policy was formally struck down.

The results suggest redlining resulted in large and sustained shifts in capital investment across proximate neighborhoods. Although black neighborhoods were far more likely to receive the worst credit rating, I show the effects of redlining on housing supply and population density are not driven by unobservable forms of discrimination stemming from a neighborhood's historical racial composition. I also show that the difference-in-differences effects of redlining hold even in neighborhoods that were initially homogeneously white at the onset of the policy. My

results indicate that the HOLC credit ratings themselves had a first-order impact on whether 
and where homes were built and the density of economic activity for decades to come. Due to the HOLC maps' national scale, local influence, and undeniable connection to race, redlining sheds new light on our understanding of urban decline and patterns of racial segregation. The policy's impact on the trajectory of thousands of neighborhoods has implications for intergenerational mobility and economic opportunity for millions of American families. 


\section{References}

[1] Aaronson, D., Hartley, D., \& Mazumder, B. (2017). The Effects of the 1930s HOLC "Redlining" Maps Federal Reserve Bank of Chicago Working Paper (No. WP-2017-12).

[2] Ananat, E. O. (2011). The wrong side (s) of the tracks: The causal effects of racial segregation on urban poverty and inequality. American Economic Journal: Applied Economics, $3(2), 34-66$.

[3] Anders, Jonn (2018) "The Long Run Effects of De Jure Discrimination in the Credit Market: How Redlining Increased Crime" WP https://johnanders625665825.files.wordpress.com/2018/12/anders_redlining_12_16_2018.pdf

[4] Appel, Ian and Jordan Nickerson (2016) "Pockets of Poverty: The Long-Term Effects of Redlining," Available at SSRN: https://ssrn.com/abstract $=2852856$ or http://dx.doi.org/10.2139/ssrn.2852856

[5] Avery, R. B., Beeson, P. E., \& Sniderman, M. S. (1999). Neighborhood information and home mortgage lending. Journal of Urban Economics, 45(2), 287-310.

[6] Badger, Emily. "The Long, Painful and Repetitive History of How Baltimore Became Baltimore." Washington Post. The Washington Post, 29 Apr. 2015. Web. 17 Mar. 2016.

[7] Bayer, P., \& McMillan, R. (2005). Racial sorting and neighborhood quality (No. w11813). National Bureau of Economic Research.

[8] Bayer, P., Ferreira, F., \& McMillan, R. (2007). A unified framework for measuring preferences for schools and neighborhoods. Journal of political economy, 115(4), 588-638.

[9] Baum-Snow, N. (2007). Did highways cause suburbanization?. The Quarterly Journal of Economics, 775-805.

[10] Baum-Snow, N., \& Lutz, B. F. (2011). School desegregation, school choice, and changes in residential location patterns by race. The American economic review, 101(7), 3019-3046.

[11] Benston, G. J., Horsky, D., \& Weingartner, H. M. (1978). An empirical study of mortgage redlining (No. 5). New York University, Graduate School of Business Administration, Salomon Brothers Center for the Study of Financial Institutions.

[12] Black, Sandra and Philip Strahan (2002) "Entrepreneurship and bank credit availability." The Journal of Finance 57(6), 2807-2833.

[13] Bleakley, H., \& Lin, J. (2012). Portage and path dependence. The Quarterly Journal of Economics, 127(2):587-644.

[14] Boustan, L. P. (2010). Was postwar suburbanization "White Flight"? Evidence from the black migration. The Quarterly Journal of Economics, 125(1), 417-443.

[15] Brinkman, J. \& Lin, J. (2017). Freeway Revolts! Working Paper

[16] Brennan, J. F. (2015). The impact of Depression-era HomeownersâĂŹ Loan Corporation lending in Greater Cleveland, Ohio. Urban Geography, 36(1), 1-28.

[17] Brevoort, K. P. (2011). Credit card redlining revisited. Review of Economics and Statistics, 93(2), 714-724.

[18] Brooks, L. \& Lutz, B.F. (2014). Vestiges of Transit: Urban Persistence at a Micro Scale. working paper 
[19] Busso, M., Gregory, J., \& Kline, P. (2013). Assessing the incidence and efficiency of a prominent place based policy. The American Economic Review, 103(2), 897-947.

[20] Cohen-Cole, E. (2011). Credit card redlining. Review of Economics and Statistics, 93(2), 700-713.

[21] Charles, K. K., \& Hurst, E. (2002). The transition to home ownership and the black-white wealth gap. Review of Economics and Statistics, 84(2), 281-297.

[22] Coates, Ta-Nehisi (2014, June) The Case for Reparations. The Atlantic Monthly http://www.theatlantic.com/magazine/archive/2014/06/the-case-for-reparations/361631/

[23] Courtemanche, C., \& Snowden, K. (2011). Repairing a mortgage crisis: HOLC lending and its impact on local housing markets. The Journal of Economic History, 71(02), 307-337.

[24] Crossney, K. B., \& Bartelt, D. W. (2005). The legacy of the home ownersâĂŹ loan corporation. Housing Policy Debate, 16(3-4), 547-574.

[25] Crossney, K. B., \& Bartelt, D. W. (2005). Residential security, risk, and race: The Home Owners' Loan Corporation and mortgage access in two cities. Urban Geography, 26(8), 707-736.

[26] Chetty, R., Friedman, J. N., Hilger, N., Saez, E., Schanzenbach, D. W., \& Yagan, D. (2011). How does your kindergarten classroom affect your earnings? Evidence from Project STAR. The Quarterly Journal of Economics, 126(4), 1593-1660.

[27] Chetty, R., Hendren, N., \& Katz, L. F. (2016). The effects of exposure to better neighborhoods on children: New evidence from the Moving to Opportunity experiment. The American Economic Review, 106(4), 855-902.

[28] Chetty, R., Hendren, N., Kline, P., \& Saez, E. (2014). Where is the land of opportunity? The geography of intergenerational mobility in the United States. The Quarterly Journal of Economics, 129(4), 1553-1623.

[29] Davis, D. R., \& Weinstein, D. E. (2002). Bones, bombs, and break points: the geography of economic activity. The American Economic Review, 92(5), 1269-1289.

[30] Fishback, P. V., Flores-Lagunes, A., Horrace, W. C., Kantor, S., \& Treber, J. (2011). The Influence of the Home Owners' Loan Corporation on Housing Markets During the 1930s. Review of Financial Studies, 24(6), 1782-1813.

[31] Fishback, Price, 2014, "Panel Discussion on Saving the Neighborhood: Part III," Arizona Law Review, available at http://arizonalawreview.org/fishback/.

[32] Glaeser, E. L., \& Gyourko, J. (2005). Urban decline and durable housing. Journal of political economy, 113(2), 345-375.

[33] Gordon, A. (2005). The creation of homeownership: How New Deal changes in banking regulation simultaneously made homeownership accessible to whites and out of reach for blacks. The Yale Law Journal, 186-226.

[34] Greer, J. (2013). The Home Owners' Loan Corporation and the development of the residential security maps. Journal of Urban History, 39(2), 275-296. http://juh.sagepub.com/content/39/2/275.full.pdf

[35] Harriss, C. Lowell. History and Policies of the Home Owners Loan Corporation. Cambridge: NBER, 1951. 
[36] Hernandez, J. (2009). Redlining revisited: mortgage lending patterns in Sacramento 1930âĂŞ2004. International Journal of Urban and Regional Research, 33(2), 291-313.

[37] Hillier, A. E. (2003). Redlining and the home owners' loan corporation. Journal of Urban History, 29(4), 394-420.

[38] Hillier, A. E. (2003). Spatial analysis of historical redlining: A methodological explanation. Departmental Papers (City and Regional Planning), 9.

[39] Hornbeck, R., \& Keniston, D. (2017). Creative destruction: Barriers to urban growth and the Great Boston fire of 1872. American Economic Review.

[40] Jackson, K. T. (1980). Race, Ethnicity, and Real Estate Appraisal:" The Home Owners Loan Corporation and the Federal Housing Administration". Journal of Urban History, 6(4), 419.

[41] Jacobs, J. (1961). The death and life of great American cities. New-York, NY: Vintage.

[42] Katz, L. F., Kling, J. R., \& Liebman, J. B. (2001). Moving to opportunity in Boston: Early results of a randomized mobility experiment. The Quarterly Journal of Economics, 116(2), 607-654.

[43] Kline, P., \& Moretti, E. (2014). Local economic development, agglomeration economies, and the big push: 100 years of evidence from the Tennessee Valley Authority. The Quarterly Journal of Economics, 129(1), 275-331.

[44] Lee, S., \& Lin, J. (2013). Natural amenities, neighborhood dynamics, and persistence in the spatial distribution of income.

[45] Lin, J. (2015). The puzzling persistence of place. Business Review, (Q2), 1-8.

[46] Logan, John R., Zengwang Xu, and Brian Stults. 2014. "Interpolating US Decennial Census Tract Data from as Early as 1970 to 2010: A Longitudinal Tract Database" The Professional Geographer 66(3): 412âĂŞ420.

[47] Manson, S., Schroeder, J., Van Riper, D., and Ruggles, S. IPUMS National Historical Geographic Information System: Version 12.0 [Database]. Minneapolis: University of Minnesota. 2017. http://doi.org/10.18128/D050.V12.0

[48] Meltzer, A. H. (1974). Credit availability and economic decisions: Some evidence from the mortgage and housing markets. The Journal of Finance, 29(3), 763-777.

[49] Robert K. Nelson, LaDale Winling, Richard Marciano, Nathan Connolly, et al., "Mapping Inequality," American Panorama, ed. Robert K. Nelson and Edward L. Ayers, accessed March 31, 2017, https://dsl.richmond.edu/panorama/redlining

[50] Redding, S.J. \& Daniel Sturm (2016) Estimating Neighborhood Effects: Evidence from War-Time Destruction in London. http://www.princeton.edu/ reddings/papers/LWW29Mar16.pdf

[51] Rose, J. D. (2011). The incredible HOLC? Mortgage relief during the Great Depression. Journal of Money, Credit and Banking, 43(6), 1073-1107.

[52] Rosenthal, S. S. (2008). Old homes, externalities, and poor neighborhoods. A model of urban decline and renewal. Journal of Urban Economics, 63(3), 816-840.

[53] Rothstein, Richard (2014) "Modern Segregation" Presentation to the Atlantic Live Conference. 6 Mar. 2014. Washington, DC. http://files.eric.ed.gov/fulltext/ED558146.pdf 
[54] Rothstein, Richard (2014) "The Making of Ferguson: Public Policies at the Root of its Troubles" Economic Policy Institute. 15 Oct. 2014. Washington, DC. http://www.epi.org/files/2014/making-of-ferguson-final.pdf

[55] Sampson, R. J., \& Sharkey, P. (2008). Neighborhood selection and the social reproduction of concentrated racial inequality. Demography, 45(1), 1-29.

[56] Schill, M. H., \& Wachter, S. M. (1995). The spatial bias of federal housing law and policy: Concentrated poverty in urban America. University of Pennsylvania Law Review, 143(5), 1285-1342.

[57] Shertzer, A., \& Walsh, R. P. (2016). Racial sorting and the emergence of segregation in American cities (No. w22077). National Bureau of Economic Research.

[58] Siodla, J. (2015). Razing San Francisco: The 1906 disaster as a natural experiment in urban redevelopment. Journal of Urban Economics, 89, 48-61.

[59] Sugrue, T. J. (2014). The origins of the urban crisis: Race and inequality in postwar Detroit. Princeton University Press.

[60] Thompson, J. P., \& Suarez, G. (2015). Exploring the racial wealth gap using the survey of consumer finances.

[61] Craig S. Wilder, A Covenant with Color: Race and Social Power in Brooklyn (New York, Columbia University Press, 2000).

[62] Woods, L. L. (2012). The Federal Home Loan Bank Board, redlining, and the national proliferation of racial lending discrimination, 1921-1950. Journal of Urban History, 38(6), 1036-1059.

[63] Woods II, L. L. (2013). Almost "No Negro Veteran...Could get a loan":African Americans, the GI Bill, and the NAACP Campaign against residential segregation, 1917-1960. Journal of African American History, 98(3), 392-417. 


\section{Appendix}

\subsection{HOLC Instructions to Local Financiers}

"Four classifications are used as indicated by the legend, namely: First, Second, Third and Fourth grades. The codes letters and colors are A, B, C, and D, and Green, Blue, Yellow and Red respectively. In establishing the grade of an area, such factors as these are considered: intensity of the sale and rental demand; percentage of home ownership; age and type of building; economic stability of the area; social status of the population; sufficiency of public utilities, accessibility of schools, churches, and business centers; transportation methods; topography of the area; and the restrictions set up to protect the neighborhoods. The price level of homes is not the guiding factor.

The First grade of A areas are "hot spots"; they are not fully built up. In nearly all instances they are the new well planned sections of the city, and almost synonymous with the area where good mortgage lenders with available funds are willing to make their maximum loans to be amortized over 10-15 year period - perhaps up to $75-80 \%$ of the appraisal. They are homogeneous; in demand as residential locations in "good times" or "bad"; hence on the upgrade. The Second grade or B areas, as a rule, are completely developed. They are like a 1935 automobile - still good, but not what the people are buying today who can afford a new one. They are neighborhoods where good mortgage lenders will have a tendency to hold loan commitments $10-15 \%$ under the limit. The Third grade or $\mathbf{C}$ areas are characterized by age, obsolescence, and change of style; expiring restrictions or lack of them; infiltration of a lower grade population; the presence of influences with increase sales resistance such as inadequate transportation, insufficient utilities, perhaps heavy tax burdens, poor maintenance of homes etc. "Jerry" built areas are included, as well as neighborhoods lacking homogeneity. Generally, these have reached the transition period. Good mortgage lenders are more conservative in the Third grade or $\mathrm{C}$ areas and hold loan commitments under the lending ration for the A and B areas. The fourth grade or D areas represent those neighborhoods in which the things that are now taking place in the $\mathrm{C}$ neighborhoods, have already happened. They are characterized by detrimental influences in a pronounced degree, undesirable population of an infiltration of it. Low percentage of home ownership, very poor maintenance and often vandalism prevail. Unstable incomes of the people and difficult collections are usually prevalent. The areas are broader than the so-called slum districts. Some mortgage lenders may refuse to make loans in these neighborhoods and others will lend only on a conservative basis.

These maps and descriptions have been carefully checked with competent local real estate brokers and mortgage lenders, and we believe they represent a fair and composite opinion of the best qualified local people. In using them we do not mean to imply that good mortgages do not exist or cannot be made in the Third and Fourth grade areas, but we do think they should be made as serviced on a different basis than in the First and Second grade areas." (Emphasis Added) ${ }^{33}$

\footnotetext{
${ }_{33}$ Residential Security Map of Baltimore, MD 1937 https://jscholarship.library.jhu.edu/handle/1774.2/32621
} 


\subsection{City Level Statistics}

\subsubsection{Redlining by Race in the Full Sample of Cities, 1940}

\begin{tabular}{|c|c|c|c|c|c|}
\hline \multirow[t]{2}{*}{ City } & \multirow[t]{2}{*}{ Population } & \multicolumn{2}{|c|}{ Black } & \multicolumn{2}{|c|}{ White } \\
\hline & & Population Share & Share Redlined & Population Share & Share Redlined \\
\hline Chicago, Illinois & 3400000 & 8 & 98 & 92 & 35 \\
\hline Los Angeles, California & 2790000 & 3 & 86 & 95 & 26 \\
\hline Brooklyn, New York & 2700000 & 4 & 90 & 96 & 46 \\
\hline Detroit, Michigan & 2070000 & 8 & 94 & 92 & 37 \\
\hline Philadelphia, Pennsylvania & 1930000 & 13 & 89 & 87 & 50 \\
\hline Manhattan, New York & 1890000 & 16 & 90 & 83 & 58 \\
\hline Pittsburgh, Pennsylvania & 1410000 & 6 & 66 & 94 & 26 \\
\hline Bronx, New York & 1390000 & 2 & 81 & 98 & 46 \\
\hline Queens, New York & 1300000 & 2 & 48 & 98 & 12 \\
\hline Cleveland, Ohio & 1230000 & 7 & 94 & 93 & 34 \\
\hline St.Louis, Missouri & 1090000 & 11 & 82 & 89 & 24 \\
\hline Baltimore, Maryland & 860000 & 19 & 90 & 81 & 33 \\
\hline Minneapolis, Minnesota & 820000 & 1 & 31 & 99 & 12 \\
\hline Boston, Massachusetts & 770000 & 3 & 93 & 97 & 43 \\
\hline Hudson County, New Jersey & 650000 & 2 & 82 & 97 & 48 \\
\hline San Francisco, California & 630000 & 1 & 59 & 95 & 35 \\
\hline Milwaukee Co., Wisconsin & 590000 & 2 & 98 & 98 & 45 \\
\hline Buffalo, New York & 580000 & 3 & 5 & 97 & 4 \\
\hline New Orleans, Louisiana & 490000 & 29 & 88 & 70 & 49 \\
\hline Oakland, California & 490000 & 3 & 79 & 96 & 26 \\
\hline Indianapolis, Indiana & 450000 & 12 & 87 & 88 & 40 \\
\hline Atlanta, Georgia & 440000 & 29 & 77 & 71 & 30 \\
\hline Essex County, New Jersey & 430000 & 11 & 83 & 89 & 46 \\
\hline Greater Kansas City, Missouri & 400000 & 10 & 96 & 90 & 59 \\
\hline Seattle, Washington & 370000 & 1 & 69 & 96 & 20 \\
\hline Louisville, Kentucky & 340000 & 14 & 77 & 86 & 33 \\
\hline Denver, Colorado & 320000 & 2 & 91 & 97 & 32 \\
\hline Rochester, New York & 320000 & 1 & 83 & 99 & 29 \\
\hline Dallas, Texas & 320000 & 16 & 36 & 84 & 14 \\
\hline Columbus, Ohio & 310000 & 12 & 82 & 88 & 24 \\
\hline Portland, Oregon & 310000 & 1 & 58 & 98 & 24 \\
\hline Akron, Ohio & 290000 & 5 & 67 & 95 & 13 \\
\hline Toledo, Ohio & 280000 & 5 & 75 & 95 & 7 \\
\hline Birmingham, Alabama & 270000 & 41 & 96 & 59 & 56 \\
\hline Hartford, Connecticut & 250000 & 3 & 0 & 97 & 2 \\
\hline Dayton, Ohio & 220000 & 9 & 97 & 91 & 33 \\
\hline Syracuse, New York & 210000 & 1 & 82 & 99 & 26 \\
\hline Flint, Michigan & 210000 & 3 & 98 & 97 & 46 \\
\hline Richmond, Virginia & 190000 & 32 & 95 & 68 & 38 \\
\hline Staten Island, New York & 170000 & 2 & 31 & 98 & 35 \\
\hline New Haven, Connecticut & 160000 & 4 & 60 & 96 & 22 \\
\hline East St. Louis, Illinois & 150000 & 15 & 99 & 85 & 41 \\
\hline Bergen County, New Jersey & 140000 & 3 & . & 97 & . \\
\hline Lower Westchester Co., New York & 140000 & 3 & 52 & 97 & 26 \\
\hline Camden, New Jersey & 120000 & 11 & 94 & 89 & 50 \\
\hline Trenton, New Jersey & 120000 & 7 & 75 & 93 & 32 \\
\hline Cambridge, Massachusetts & 110000 & 4 & 68 & 95 & 44 \\
\hline Duluth, Minnesota & 100000 & 0 & 25 & 100 & 16 \\
\hline Macon, Georgia & 80000 & 42 & 76 & 58 & 64 \\
\hline Augusta, Georgia & 70000 & 40 & 98 & 60 & 80 \\
\hline Atlantic City, New Jersey & 60000 & 24 & 99 & 75 & 13 \\
\hline TOTAL & 34400000 & 8 & 86 & 92 & 35 \\
\hline
\end{tabular}




\subsubsection{Redlining by Race in 1930 sample}

\begin{tabular}{|c|c|c|c|c|c|}
\hline \multirow[t]{2}{*}{ City } & \multirow[t]{2}{*}{ Population } & \multicolumn{2}{|c|}{ Black } & \multicolumn{2}{|c|}{ White } \\
\hline & & Population Share & Share Redlined & Population Share & Share Redlined \\
\hline Chicago, Illinois & 3380000 & 7 & 98 & 92 & 37 \\
\hline Brooklyn, New York & 2560000 & 3 & 90 & 97 & 51 \\
\hline Manhattan, New York & 1870000 & 12 & 93 & 87 & 64 \\
\hline Detroit, Michigan & 1560000 & 8 & 96 & 92 & 45 \\
\hline Bronx, New York & 1280000 & 1 & 77 & 99 & 50 \\
\hline Los Angeles, California & 1230000 & 3 & 87 & 86 & 32 \\
\hline Cleveland, Ohio & 1110000 & 6 & 96 & 93 & 41 \\
\hline Queens, New York & 1080000 & 2 & 46 & 98 & 13 \\
\hline St.Louis, Missouri & 820000 & 11 & 87 & 88 & 35 \\
\hline Boston, Massachusetts & 780000 & 3 & 93 & 97 & 47 \\
\hline Baltimore, Maryland & 760000 & 15 & 78 & 85 & 36 \\
\hline Pittsburgh, Pennsylvania & 670000 & 8 & 78 & 92 & 38 \\
\hline Milwaukee Co., Wisconsin & 580000 & Race & Data & Not & Available \\
\hline Buffalo, New York & 570000 & 2 & 5 & 98 & 5 \\
\hline Indianapolis, Indiana & 360000 & 12 & 89 & 88 & 44 \\
\hline Columbus, Ohio & 290000 & 11 & 81 & 89 & 25 \\
\hline Syracuse, New York & 210000 & 1 & 71 & 99 & 27 \\
\hline Staten Island, New York & 160000 & 2 & 36 & 98 & 38 \\
\hline Lower Westchester Co., New York & 130000 & 3 & 35 & 97 & 32 \\
\hline TOTAL & 19400000 & 6 & 89 & 90 & 41 \\
\hline
\end{tabular}




\subsection{Border Tract Summary Statistics}

\subsubsection{Red-Yellow Border Tracts (Main Analysis)}

Summary Statistics for 1940, Standard Deviations in Parentheses

\begin{tabular}{|c|c|c|c|}
\hline & Redlined Border Tracts & Yellow Border Tracts & All Red-Yellow Border Tracts \\
\hline \multirow[t]{2}{*}{ Housing Units } & 1,624 & 1,718 & 1,693 \\
\hline & $(1,399)$ & $(1,571)$ & $(1,541)$ \\
\hline \multirow[t]{2}{*}{ Population } & 5,650 & 5,789 & 5,754 \\
\hline & $(4,876)$ & $(5,213)$ & $(5,119)$ \\
\hline \multirow[t]{2}{*}{ Density } & 21,362 & 17,834 & 18,889 \\
\hline & $(19,964)$ & $(16,204)$ & $(17,956)$ \\
\hline \multirow[t]{2}{*}{ Home Ownership } & .308 & .381 & .358 \\
\hline & $(.174)$ & $(.182)$ & $(.187)$ \\
\hline \multirow[t]{2}{*}{ Pct. Black } & .128 & .0292 & .07 \\
\hline & $(.231)$ & $(.0821)$ & $(.168)$ \\
\hline \multirow[t]{2}{*}{ Pct. White } & .866 & .969 & .926 \\
\hline & $(.233)$ & $(.0824)$ & $(.17)$ \\
\hline \multirow[t]{2}{*}{ Pct. Other } & .00582 & .0021 & .00395 \\
\hline & $(.0334)$ & $(.00959)$ & $(.025)$ \\
\hline \multirow[t]{2}{*}{ Area(sqmi) } & .82 & .814 & .877 \\
\hline & $(4.73)$ & $(1.67)$ & $(3.52)$ \\
\hline \multirow[t]{2}{*}{ Miles to City Center } & 3.85 & 4.74 & 4.37 \\
\hline & $(3.05)$ & $(3.55)$ & $(3.34)$ \\
\hline \multirow[t]{2}{*}{ Male LFPR } & .804 & .813 & .809 \\
\hline & $(.0582)$ & $(.0566)$ & $(.0567)$ \\
\hline \multirow[t]{2}{*}{ Pct. Foreign } & .144 & .14 & .14 \\
\hline & $(.103)$ & $(.0872)$ & $(.093)$ \\
\hline \multirow[t]{2}{*}{ Pct. Homes In Disrepair } & .117 & .0712 & .0884 \\
\hline & $(.119)$ & $(.0795)$ & $(.0996)$ \\
\hline \multirow[t]{2}{*}{ Pct. Homes with Radio } & .891 & .934 & .917 \\
\hline & $(.114)$ & $(.0784)$ & $(.0959)$ \\
\hline \multirow[t]{2}{*}{ Pct. Homes with Heating } & .512 & .659 & .611 \\
\hline & $(.321)$ & $(.312)$ & $(.324)$ \\
\hline \multirow[t]{2}{*}{ Pct. Homes with Fridge } & .459 & .62 & .565 \\
\hline & $(.183)$ & $(.166)$ & $(.198)$ \\
\hline \multirow[t]{2}{*}{ Median Yrs. Schooling } & 8.17 & 9.1 & 8.83 \\
\hline & $(1.53)$ & $(1.71)$ & $(1.81)$ \\
\hline \multirow[t]{2}{*}{ Share of Tracts With No Blacks } & .173 & .226 & .198 \\
\hline & $(.379)$ & $(.418)$ & $(.398)$ \\
\hline $\mathrm{N}$ & 918 & 1,137 & 2,224 \\
\hline
\end{tabular}


Summary Statistics for Select Yeras, Standard Deviations in Parentheses

\begin{tabular}{|c|c|c|c|c|c|c|c|c|c|}
\hline & \multicolumn{3}{|c|}{$\underline{\text { Red Border Tracts }}$} & \multicolumn{3}{|c|}{$\underline{\text { Yellow Border Tracts }}$} & \multicolumn{3}{|c|}{ All Border Tracts } \\
\hline & 1940 & 1970 & 2000 & 1940 & 1970 & 2000 & 1940 & 1970 & 2000 \\
\hline Housing Units & $\begin{array}{c}1,624 \\
(1,399)\end{array}$ & $\begin{array}{c}2,059 \\
(2,464)\end{array}$ & $\begin{array}{c}2,043 \\
(3,228)\end{array}$ & $\begin{array}{c}1,718 \\
(1,571)\end{array}$ & $\begin{array}{c}2,654 \\
(3,006)\end{array}$ & $\begin{array}{c}2,790 \\
(3,768)\end{array}$ & $\begin{array}{c}1,693 \\
(1,541)\end{array}$ & $\begin{array}{c}2,471 \\
(2,888)\end{array}$ & $\begin{array}{c}2,571 \\
(3,712)\end{array}$ \\
\hline Population & $\begin{array}{c}5,650 \\
(4,876)\end{array}$ & $\begin{array}{c}5,897 \\
(7,855)\end{array}$ & $\begin{array}{c}5,055 \\
(8,466)\end{array}$ & $\begin{array}{c}5,789 \\
(5,213)\end{array}$ & $\begin{array}{c}7,445 \\
(8,953)\end{array}$ & $\begin{array}{c}7,064 \\
(10,433)\end{array}$ & $\begin{array}{c}5,754 \\
(5,119)\end{array}$ & $\begin{array}{c}6,936 \\
(8,602)\end{array}$ & $\begin{array}{c}6,390 \\
(9,905)\end{array}$ \\
\hline Density & $\begin{array}{c}21,362 \\
(19,964)\end{array}$ & $\begin{array}{c}16,684 \\
(15,438)\end{array}$ & $\begin{array}{c}13,029 \\
(13,915)\end{array}$ & $\begin{array}{c}17,834 \\
(16,204)\end{array}$ & $\begin{array}{c}16,213 \\
(13,087)\end{array}$ & $\begin{array}{c}13,819 \\
(13,051)\end{array}$ & $\begin{array}{c}18,889 \\
(17,956)\end{array}$ & $\begin{array}{c}16,239 \\
(14,249)\end{array}$ & $\begin{array}{c}13,412 \\
(13,692)\end{array}$ \\
\hline Home Ownership & $\begin{array}{c}.308 \\
(.174)\end{array}$ & $\begin{array}{c}.38 \\
(.218)\end{array}$ & $\begin{array}{c}.383 \\
(.191)\end{array}$ & $\begin{array}{c}.381 \\
(.182)\end{array}$ & $\begin{array}{c}.44 \\
(.223)\end{array}$ & $\begin{array}{c}.431 \\
(.193)\end{array}$ & $\begin{array}{c}.358 \\
(.187)\end{array}$ & $\begin{array}{c}.422 \\
(.225)\end{array}$ & $\begin{array}{c}.419 \\
(.197)\end{array}$ \\
\hline Pct. Black & $\begin{array}{c}.128 \\
(.231)\end{array}$ & $\begin{array}{c}.362 \\
(.364)\end{array}$ & $\begin{array}{c}.471 \\
(.367)\end{array}$ & $\begin{array}{c}.0292 \\
(.0821)\end{array}$ & $\begin{array}{c}.271 \\
(.349)\end{array}$ & $\begin{array}{c}.406 \\
(.366)\end{array}$ & $\begin{array}{c}.07 \\
(.168)\end{array}$ & $\begin{array}{c}.302 \\
(.353)\end{array}$ & $\begin{array}{c}.426 \\
(.367)\end{array}$ \\
\hline Pct. White & $\begin{array}{c}.866 \\
(.233)\end{array}$ & $\begin{array}{c}.617 \\
(.359)\end{array}$ & $\begin{array}{c}.308 \\
(.299)\end{array}$ & $\begin{array}{c}.969 \\
(.0824)\end{array}$ & $\begin{array}{c}.712 \\
(.347)\end{array}$ & $\begin{array}{c}.372 \\
(.321)\end{array}$ & $\begin{array}{l}.926 \\
(.17)\end{array}$ & $\begin{array}{c}.68 \\
(.35)\end{array}$ & $\begin{array}{c}.358 \\
(.318)\end{array}$ \\
\hline Pct. Other & $\begin{array}{l}.00582 \\
(.0334)\end{array}$ & $\begin{array}{c}.0209 \\
(.0485)\end{array}$ & $\begin{array}{c}.221 \\
(.267)\end{array}$ & $\begin{array}{c}.0021 \\
(.00959)\end{array}$ & $\begin{array}{c}.0166 \\
(.0281)\end{array}$ & $\begin{array}{c}.222 \\
(.262)\end{array}$ & $\begin{array}{l}.00395 \\
(.025)\end{array}$ & $\begin{array}{c}.0184 \\
(.0377)\end{array}$ & $\begin{array}{l}.216 \\
(.26)\end{array}$ \\
\hline $\mathrm{N}$ & 918 & 918 & 918 & 1,137 & 1,137 & 1,137 & 2,224 & 2,224 & 2,224 \\
\hline
\end{tabular}


9.4 Initial Conditions of Border Tracts, With Controls, 1940

\begin{tabular}{|c|c|c|c|c|}
\hline & $\begin{array}{c}(1) \\
\text { Log Total Units }\end{array}$ & $\begin{array}{c}(2) \\
\text { Log Pop/sqmi }\end{array}$ & $\begin{array}{c}\text { (3) } \\
\text { Pct. Black }\end{array}$ & $\begin{array}{c}(4) \\
\text { Pct. OwnerOcc }\end{array}$ \\
\hline Redlined & $\begin{array}{l}-0.011 \\
(0.058)\end{array}$ & $\begin{array}{l}-0.034 \\
(0.075)\end{array}$ & $\begin{array}{c}0.028^{* * *} \\
(0.010)\end{array}$ & $\begin{array}{c}-0.033^{* *} \\
(0.012)\end{array}$ \\
\hline Tract Area & $\begin{array}{c}0.007 \\
(0.005)\end{array}$ & $\begin{array}{c}-0.076^{* *} \\
(0.029)\end{array}$ & $\begin{array}{l}-0.000 \\
(0.001)\end{array}$ & $\begin{array}{l}0.004^{*} \\
(0.002)\end{array}$ \\
\hline Pct.Blk in '40 & $\begin{array}{c}0.543^{* * *} \\
(0.137)\end{array}$ & $\begin{array}{c}0.751^{* * *} \\
(0.170)\end{array}$ & & $\begin{array}{l}-0.048 \\
(0.044)\end{array}$ \\
\hline LFPR in '40 & $\begin{array}{l}1.649^{* *} \\
(0.808)\end{array}$ & $\begin{array}{c}1.162 \\
(0.826)\end{array}$ & $\begin{array}{c}0.237 \\
(0.170)\end{array}$ & $\begin{array}{l}-0.070 \\
(0.117)\end{array}$ \\
\hline Pct.Foreign in '40 & $\begin{array}{c}2.781^{* * *} \\
(0.744)\end{array}$ & $\begin{array}{c}4.643^{* * *} \\
(0.794)\end{array}$ & $\begin{array}{l}0.321^{* *} \\
(0.120)\end{array}$ & $\begin{array}{l}-0.056 \\
(0.139)\end{array}$ \\
\hline Pct.Disrepair in '40 & $\begin{array}{l}-0.409 \\
(0.249)\end{array}$ & $\begin{array}{l}-0.382 \\
(0.367)\end{array}$ & $\begin{array}{c}0.203^{* * *} \\
(0.064)\end{array}$ & $\begin{array}{c}0.057 \\
(0.041)\end{array}$ \\
\hline Pct.Radio in '40 & $\begin{array}{c}2.763^{* * *} \\
(0.653)\end{array}$ & $\begin{array}{c}4.403^{* * *} \\
(0.741)\end{array}$ & $\begin{array}{l}-0.347^{*} \\
(0.196)\end{array}$ & $\begin{array}{c}0.163 \\
(0.197)\end{array}$ \\
\hline Pct.Heating in $40^{\prime}$ & $\begin{array}{c}0.350 \\
(0.275)\end{array}$ & $\begin{array}{c}0.998^{* * *} \\
(0.356)\end{array}$ & $\begin{array}{l}0.116^{*} \\
(0.066)\end{array}$ & $\begin{array}{l}-0.079 \\
(0.053)\end{array}$ \\
\hline Pct.Fridge in ' 40 & $\begin{array}{c}-1.261^{* * *} \\
(0.434)\end{array}$ & $\begin{array}{c}-2.647^{* * *} \\
(0.539)\end{array}$ & $\begin{array}{c}-0.322^{* * *} \\
(0.094)\end{array}$ & $\begin{array}{c}0.259^{* * *} \\
(0.081)\end{array}$ \\
\hline Schooling in '40 & $\begin{array}{c}0.217^{* * *} \\
(0.039)\end{array}$ & $\begin{array}{c}0.223^{* * *} \\
(0.027)\end{array}$ & $\begin{array}{l}-0.005 \\
(0.005)\end{array}$ & $\begin{array}{c}-0.018^{* * *} \\
(0.006)\end{array}$ \\
\hline Observations & 2051 & 2055 & 2053 & 2046 \\
\hline$R^{2}$ & 0.266 & 0.409 & 0.295 & 0.148 \\
\hline Sample & 1940 Border Tracts & 1940 Border Tracts & 1940 Border Tracts & 1940 Border Tracts \\
\hline $\mathrm{FE}$ & Border Segment & Border Segment & Border Segment & Border Segment \\
\hline Mean & 7.12 & 9.36 & .07 & .35 \\
\hline
\end{tabular}

Standard errors in parentheses

All specifications include City FE and cluster SEs at city level

${ }^{*} p<.10,{ }^{* *} p<.05,{ }^{* * *} p<.01$

\subsection{Difference in Differences Regressions, 1940-2010}

Pre: 1940-1970; Post: 1980-2010

\begin{tabular}{lcccc}
\hline & $(1)$ & $(2)$ & $(3)$ & $(4)$ \\
& Log Total Units & Log Pop/sqmi & Pct. Black & Pct. OwnerOcc \\
\hline Post70 X Redlined & $-0.171^{* * *}$ & $-0.190^{* * *}$ & $-0.038^{* * *}$ & $0.013^{* * *}$ \\
& $(0.039)$ & $(0.036)$ & $(0.011)$ & $(0.004)$ \\
Post-1970 & $-0.094^{* * *}$ & $-0.691^{* * *}$ & $0.231^{* * *}$ & $-0.065^{* * *}$ \\
& $(0.011)$ & $(0.010)$ & $(0.003)$ & $(0.001)$ \\
Redlined & 0.018 & 0.028 & $0.051^{* * *}$ & $-0.032^{* * *}$ \\
& $(0.040)$ & $(0.046)$ & $(0.015)$ & $(0.011)$ \\
\hline Observations & 12325 & 12330 & 12327 & 12320 \\
$R^{2}$ & 0.176 & 0.248 & 0.412 & 0.201 \\
Sample & Border Tracts & Border Tracts & Border Tracts & Border Tracts \\
Mean & 7.28 & 9.22 & .34 & .4 \\
\hline
\end{tabular}

Standard errors in parentheses

All specifications include controls, border segment FE, city-by-year FE and cluster SEs at city level

${ }^{*} p<.10,{ }^{* *} p<.05,{ }^{* * *} p<.01$ 


\subsection{Difference in Differences Regressions, 1940-2010}

Coefficients Relative to 1940 (omitted)

\begin{tabular}{|c|c|c|c|c|}
\hline & $\begin{array}{c}(1) \\
\text { Log Total Units }\end{array}$ & $\begin{array}{c}(2) \\
\log \text { Pop/sqmi }\end{array}$ & $\begin{array}{c}(3) \\
\text { Pct. Black }\end{array}$ & $\begin{array}{c}\text { (4) } \\
\text { Pct. OwnerOcc }\end{array}$ \\
\hline Redlined X 1970 & $\begin{array}{c}-0.198^{* * *} \\
(0.052)\end{array}$ & $\begin{array}{c}-0.220^{* * *} \\
(0.046)\end{array}$ & $\begin{array}{l}-0.007 \\
(0.017)\end{array}$ & $\begin{array}{c}0.006 \\
(0.005)\end{array}$ \\
\hline Redlined X 1980 & $\begin{array}{c}-0.248^{* * *} \\
(0.057)\end{array}$ & $\begin{array}{c}-0.276^{* * *} \\
(0.051)\end{array}$ & $\begin{array}{l}-0.027 \\
(0.019)\end{array}$ & $\begin{array}{l}0.012^{* *} \\
(0.006)\end{array}$ \\
\hline Redlined X 1990 & $\begin{array}{c}-0.265^{* * *} \\
(0.065)\end{array}$ & $\begin{array}{c}-0.291^{* * *} \\
(0.059)\end{array}$ & $\begin{array}{l}-0.037^{*} \\
(0.019)\end{array}$ & $\begin{array}{l}0.014^{* *} \\
(0.005)\end{array}$ \\
\hline Redlined X 2000 & $\begin{array}{c}-0.285^{* * *} \\
(0.068)\end{array}$ & $\begin{array}{c}-0.308^{* * *} \\
(0.059)\end{array}$ & $\begin{array}{c}-0.047^{* *} \\
(0.018)\end{array}$ & $\begin{array}{l}0.017^{* * *} \\
(0.005)\end{array}$ \\
\hline Redlined X 2010 & $\begin{array}{c}-0.283^{* * *} \\
(0.070)\end{array}$ & $\begin{array}{c}-0.324^{* * *} \\
(0.062)\end{array}$ & $\begin{array}{c}-0.056^{* * *} \\
(0.017)\end{array}$ & $\begin{array}{c}0.021^{* * *} \\
(0.006)\end{array}$ \\
\hline Redlined & $\begin{array}{l}0.114^{*} \\
(0.058)\end{array}$ & $\begin{array}{l}0.136^{* *} \\
(0.062)\end{array}$ & $\begin{array}{c}0.055^{* * *} \\
(0.016)\end{array}$ & $\begin{array}{c}-0.035^{* * *} \\
(0.012)\end{array}$ \\
\hline 1970 & $\begin{array}{c}0.159^{* * *} \\
(0.014)\end{array}$ & $\begin{array}{c}-0.134^{* * *} \\
(0.012)\end{array}$ & $\begin{array}{c}0.205^{* * *} \\
(0.005)\end{array}$ & $\begin{array}{c}0.081^{* * *} \\
(0.001)\end{array}$ \\
\hline 1980 & $\begin{array}{c}0.060^{* * *} \\
(0.016)\end{array}$ & $\begin{array}{c}-0.371^{* * *} \\
(0.014)\end{array}$ & $\begin{array}{c}0.228^{* * *} \\
(0.005)\end{array}$ & $\begin{array}{c}0.040^{* * *} \\
(0.002)\end{array}$ \\
\hline 1990 & $\begin{array}{l}-0.027 \\
(0.018)\end{array}$ & $\begin{array}{c}-0.495^{* * *} \\
(0.016)\end{array}$ & $\begin{array}{c}0.251^{* * *} \\
(0.005)\end{array}$ & $\begin{array}{c}0.001 \\
(0.001)\end{array}$ \\
\hline 2000 & $\begin{array}{c}-0.063^{* * *} \\
(0.018)\end{array}$ & $\begin{array}{c}-0.519^{* * *} \\
(0.016)\end{array}$ & $\begin{array}{c}0.323^{* * *} \\
(0.005)\end{array}$ & $\begin{array}{c}-0.008^{* * *} \\
(0.001)\end{array}$ \\
\hline 2010 & $\begin{array}{c}-0.150^{* * *} \\
(0.019)\end{array}$ & $\begin{array}{c}-0.654^{* * *} \\
(0.017)\end{array}$ & $\begin{array}{c}0.357^{* * *} \\
(0.005)\end{array}$ & $\begin{array}{c}-0.068^{* * *} \\
(0.002)\end{array}$ \\
\hline Observations & 12325 & 12330 & 12327 & 12320 \\
\hline$R^{2}$ & 0.180 & 0.252 & 0.412 & 0.201 \\
\hline Sample & Border Tracts & Border Tracts & Border Tracts & Border Tracts \\
\hline Mean & 7.28 & 9.22 & .34 & .4 \\
\hline
\end{tabular}

Standard errors in parentheses

All specifications include controls, City-by-Year FE, Border Segment FE, and cluster SEs at city level

${ }^{*} p<.10,{ }^{* *} p<.05,{ }^{* * *} p<.01$ 


\subsection{Heterogeneous Effects:}

Triple Difference by Initial Share of Black Residents

9.7a. Effects of Redlining - Triple Difference with Percent Black in 1940 Pre: 1940; Post: 1970

\begin{tabular}{|c|c|c|c|}
\hline & $\begin{array}{c}(1) \\
\text { Log Total Units }\end{array}$ & $\begin{array}{c}(2) \\
\text { Log Pop/sqmi }\end{array}$ & $\begin{array}{c}(3) \\
\text { Pct. OwnerOcc }\end{array}$ \\
\hline \multirow[t]{2}{*}{ Post40 X Redlined } & $-0.143^{* *}$ & $-0.169^{* * *}$ & 0.004 \\
\hline & $(0.067)$ & $(0.055)$ & $(0.007)$ \\
\hline \multirow[t]{2}{*}{ Post-1940 } & $0.232^{* * *}$ & -0.029 & $0.093^{* * *}$ \\
\hline & $(0.032)$ & $(0.035)$ & $(0.005)$ \\
\hline \multirow[t]{2}{*}{ Redlined } & 0.010 & -0.039 & $-0.025^{*}$ \\
\hline & $(0.078)$ & $(0.074)$ & $(0.014)$ \\
\hline \multirow[t]{2}{*}{ Post40 X Redlined X 1-10 Pct.Blk in '40 } & -0.111 & -0.083 & $0.018^{*}$ \\
\hline & $(0.106)$ & $(0.096)$ & $(0.009)$ \\
\hline \multirow[t]{2}{*}{ Post40 X Redlined X 10-25 Pct.Blk in '40 } & -0.102 & -0.089 & -0.014 \\
\hline & $(0.122)$ & $(0.119)$ & $(0.020)$ \\
\hline \multirow[t]{2}{*}{ Post40 X Redlined X > 25 Pct.Blk in ' 40} & -0.115 & -0.027 & $-0.051^{* *}$ \\
\hline & $(0.203)$ & $(0.225)$ & $(0.025)$ \\
\hline \multirow[t]{2}{*}{ Redlined X 1-10 Pct.Blk in '40 } & 0.153 & $0.268^{* *}$ & -0.024 \\
\hline & $(0.104)$ & $(0.117)$ & $(0.015)$ \\
\hline \multirow[t]{2}{*}{ Redlined X 10-25 Pct.Blk in '40 } & -0.085 & -0.046 & 0.017 \\
\hline & $(0.127)$ & $(0.126)$ & $(0.027)$ \\
\hline \multirow[t]{2}{*}{ Redlined X >25 Pct.Blk in '40 } & -0.031 & 0.271 & -0.003 \\
\hline & $(0.136)$ & $(0.244)$ & $(0.043)$ \\
\hline \multirow[t]{2}{*}{ Post40 X 1-10 Pct.Blk in '40 } & -0.087 & $-0.146^{* *}$ & $-0.024^{* *}$ \\
\hline & $(0.063)$ & $(0.067)$ & $(0.009)$ \\
\hline \multirow[t]{2}{*}{ Post40 X 10-25 Pct.Blk in '40 } & $-0.159^{*}$ & $-0.194^{*}$ & -0.001 \\
\hline & $(0.095)$ & $(0.104)$ & $(0.019)$ \\
\hline \multirow[t]{2}{*}{ Post $40 \mathrm{X}>25$ Pct.Blk in ' 40} & 0.059 & -0.060 & $0.055^{* * *}$ \\
\hline & $(0.190)$ & $(0.186)$ & $(0.019)$ \\
\hline \multirow[t]{2}{*}{ 1-10 Pct.Blk in '40 } & -0.063 & -0.047 & -0.013 \\
\hline & $(0.082)$ & $(0.084)$ & $(0.009)$ \\
\hline \multirow[t]{2}{*}{$10-25$ Pct.Blk in '40 } & $0.213^{*}$ & $0.295^{*}$ & $-0.045^{* *}$ \\
\hline & $(0.113)$ & $(0.147)$ & $(0.017)$ \\
\hline \multirow[t]{2}{*}{$>25$ Pct.Blk in '40 } & $0.276^{*}$ & 0.111 & -0.047 \\
\hline & $(0.160)$ & $(0.221)$ & $(0.031)$ \\
\hline Observations & 4106 & 4110 & 4101 \\
\hline$R^{2}$ & 0.186 & 0.222 & 0.287 \\
\hline Sample & Border Tracts & Border Tracts & Border Tracts \\
\hline Mean & 7.26 & 9.38 & .38 \\
\hline
\end{tabular}


9.7b. Effects of Repeal - Triple Difference with Percent Black in 1940 Pre: 1940-1970; Post: 1980-2010

\begin{tabular}{|c|c|c|c|}
\hline & $\begin{array}{c}(1) \\
\text { Log Total Units }\end{array}$ & $\begin{array}{c}(2) \\
\text { Log Pop/sqmi }\end{array}$ & $\begin{array}{c}(3) \\
\text { Pct. OwnerOcc }\end{array}$ \\
\hline Post70 X Redlined & $\begin{array}{c}-0.105^{* *} \\
(0.046)\end{array}$ & $\begin{array}{c}-0.127^{* * *} \\
(0.039)\end{array}$ & $\begin{array}{l}0.009^{*} \\
(0.005)\end{array}$ \\
\hline Post-1970 & $\begin{array}{c}-0.112^{* * *} \\
(0.022)\end{array}$ & $\begin{array}{c}-0.598^{* * *} \\
(0.023)\end{array}$ & $\begin{array}{c}-0.077^{* * *} \\
(0.004)\end{array}$ \\
\hline Redlined & $\begin{array}{l}-0.004 \\
(0.052)\end{array}$ & $\begin{array}{l}-0.046 \\
(0.049)\end{array}$ & $\begin{array}{l}-0.024^{*} \\
(0.013)\end{array}$ \\
\hline Post70 X Redlined X 1-10 Pct.Blk in '40 & $\begin{array}{l}-0.087 \\
(0.072)\end{array}$ & $\begin{array}{l}-0.068 \\
(0.062)\end{array}$ & $\begin{array}{c}0.000 \\
(0.010)\end{array}$ \\
\hline Post70 X Redlined X 10-25 Pct.Blk in '40 & $\begin{array}{l}-0.030 \\
(0.088)\end{array}$ & $\begin{array}{c}0.038 \\
(0.082)\end{array}$ & $\begin{array}{l}-0.005 \\
(0.012)\end{array}$ \\
\hline Post70 X Redlined X $>25$ Pct.Blk in '40 & $\begin{array}{l}-0.217^{*} \\
(0.129)\end{array}$ & $\begin{array}{l}-0.174 \\
(0.141)\end{array}$ & $\begin{array}{l}-0.025 \\
(0.023)\end{array}$ \\
\hline Redlined X 1-10 Pct.Blk in '40 & $\begin{array}{c}0.088 \\
(0.084)\end{array}$ & $\begin{array}{l}0.214^{* *} \\
(0.097)\end{array}$ & $\begin{array}{l}-0.011 \\
(0.016)\end{array}$ \\
\hline Redlined X 10-25 Pct.Blk in '40 & $\begin{array}{l}-0.157 \\
(0.111)\end{array}$ & $\begin{array}{l}-0.138 \\
(0.093)\end{array}$ & $\begin{array}{c}0.022 \\
(0.027)\end{array}$ \\
\hline Redlined X >25 Pct.Blk in '40 & $\begin{array}{c}0.029 \\
(0.100)\end{array}$ & $\begin{array}{l}0.324^{*} \\
(0.193)\end{array}$ & $\begin{array}{l}-0.017 \\
(0.041)\end{array}$ \\
\hline Post70 X 1-10 Pct.Blk in '40 & $\begin{array}{l}-0.067 \\
(0.042)\end{array}$ & $\begin{array}{c}-0.110^{* *} \\
(0.044)\end{array}$ & $\begin{array}{l}0.015^{* *} \\
(0.007)\end{array}$ \\
\hline Post70 X 10-25 Pct.Blk in '40 & $\begin{array}{c}-0.205^{* * *} \\
(0.070)\end{array}$ & $\begin{array}{c}-0.270^{* * *} \\
(0.068)\end{array}$ & $\begin{array}{c}0.028^{* * *} \\
(0.010)\end{array}$ \\
\hline Post70 X >25 Pct.Blk in '40 & $\begin{array}{c}0.027 \\
(0.113)\end{array}$ & $\begin{array}{l}-0.061 \\
(0.113)\end{array}$ & $\begin{array}{l}0.051^{* *} \\
(0.021)\end{array}$ \\
\hline 1-10 Pct.Blk in '40 & $\begin{array}{l}-0.064 \\
(0.072)\end{array}$ & $\begin{array}{l}-0.078 \\
(0.073)\end{array}$ & $\begin{array}{c}-0.028^{* *} \\
(0.011)\end{array}$ \\
\hline 10-25 Pct.Blk in '40 & $\begin{array}{l}0.216^{* *} \\
(0.095)\end{array}$ & $\begin{array}{c}0.294^{* * *} \\
(0.103)\end{array}$ & $\begin{array}{c}-0.056^{* * *} \\
(0.016)\end{array}$ \\
\hline$>25$ Pct.Blk in '40 & $\begin{array}{l}0.292^{* *} \\
(0.144)\end{array}$ & $\begin{array}{c}0.063 \\
(0.202) \\
\end{array}$ & $\begin{array}{l}-0.038 \\
(0.029)\end{array}$ \\
\hline Observations & 12325 & 12330 & 12320 \\
\hline$R^{2}$ & 0.183 & 0.253 & 0.205 \\
\hline Sample & Border Tracts & Border Tracts & Border Tracts \\
\hline Mean & 7.28 & 9.22 & .4 \\
\hline
\end{tabular}


9.8 Robustness: Redlining in Homogeneous White Neighborhoods

Effects of Redlining and Repeal, 1940-2010

All Red-Yellow Border Tracts (L) vs Border Tracts With No Black Residents in 1940 (R)
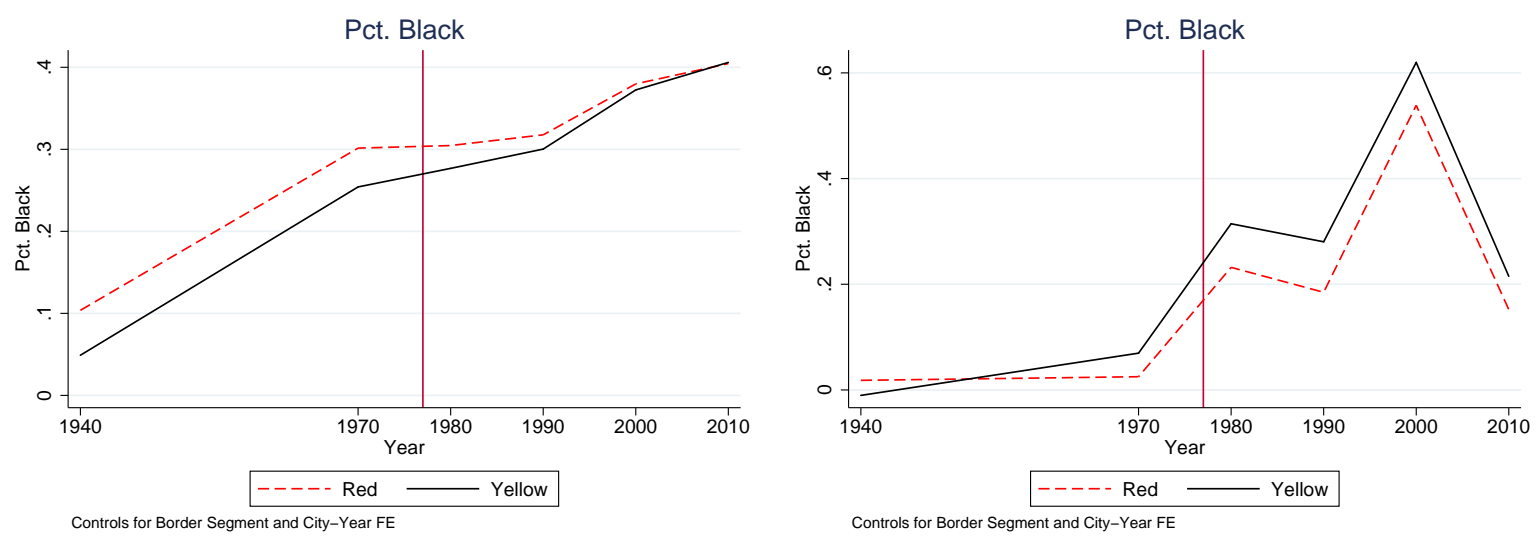


\subsection{Robustness: Border Segment FE vs. Matched Pair FE}

Effects of Redlining - Pre: 1940; Post: 1970

\begin{tabular}{|c|c|c|c|c|}
\hline & \multicolumn{2}{|c|}{ Log Total Units } & \multicolumn{2}{|c|}{ Log Pop/sqmi } \\
\hline & (1) & $(2)$ & (3) & $(4)$ \\
\hline & Border Segment FE & Matched Pair FE & Border Segment FE & Matched Pair FE \\
\hline \multirow[t]{2}{*}{ Post40 X Redlined } & $-0.198^{* * *}$ & -0.043 & $-0.220^{* * *}$ & $-0.063^{*}$ \\
\hline & $(0.051)$ & $(0.032)$ & $(0.045)$ & $(0.035)$ \\
\hline \multirow[t]{2}{*}{ Post-1940 } & $0.159^{* * *}$ & $-0.061^{* * *}$ & $-0.134^{* * *}$ & $-0.356^{* * *}$ \\
\hline & $(0.014)$ & $(0.022)$ & $(0.012)$ & $(0.023)$ \\
\hline \multirow[t]{2}{*}{ Redlined } & 0.043 & -0.043 & 0.046 & $-0.070^{*}$ \\
\hline & $(0.058)$ & $(0.030)$ & $(0.065)$ & $(0.036)$ \\
\hline Observations & 4106 & 1830 & 4110 & 1830 \\
\hline$R^{2}$ & 0.180 & 0.169 & 0.217 & 0.195 \\
\hline Sample & Border Tracts & Nearest Match & Border Tracts & Nearest Match \\
\hline Mean & 7.26 & 7.26 & 9.38 & 9.65 \\
\hline \multicolumn{5}{|c|}{ Standard errors in parentheses } \\
\hline \multicolumn{5}{|c|}{$\begin{array}{l}\text { All specifications include controls } \\
{ }^{*} p<.10,{ }^{* *} p<.05,{ }^{* * *} p<.01\end{array}$} \\
\hline \multicolumn{5}{|c|}{ Effects of Repeal - Pre: 1940-1970; Post: 1980-2010 } \\
\hline & \multicolumn{2}{|c|}{ Log Total Units } & \multicolumn{2}{|c|}{ Log Pop/sqmi } \\
\hline & (1) & (2) & (3) & (4) \\
\hline & Border Segment FE & Matched Pair FE & Border Segment FE & Matched Pair FE \\
\hline \multirow[t]{2}{*}{ Post70 X Redlined } & $-0.171^{* * *}$ & $-0.069^{* *}$ & $-0.190^{* * *}$ & $-0.085^{* * *}$ \\
\hline & $(0.039)$ & $(0.026)$ & $(0.036)$ & $(0.029)$ \\
\hline \multirow[t]{2}{*}{ Post-1970 } & $-0.180^{* * *}$ & $-0.617^{* * *}$ & $-0.395^{* * *}$ & $-1.108^{* * *}$ \\
\hline & $(0.011)$ & $(0.017)$ & $(0.010)$ & $(0.020)$ \\
\hline \multirow[t]{2}{*}{ Redlined } & 0.018 & -0.037 & 0.028 & $-0.060^{*}$ \\
\hline & $(0.040)$ & $(0.026)$ & $(0.046)$ & $(0.033)$ \\
\hline Observations & 12325 & 5490 & 12330 & 5490 \\
\hline$R^{2}$ & 0.176 & 0.259 & 0.248 & 0.425 \\
\hline Sample & Border Tracts & Nearest Match & Border Tracts & Nearest Match \\
\hline Mean & 7.28 & 7.2 & 9.22 & 9.4 \\
\hline
\end{tabular}

Standard errors in parentheses

All specifications include controls, city-by-year FE and cluster SEs at city level

${ }^{*} p<.10,{ }^{* *} p<.05,{ }^{* * *} p<.01$ 


\subsection{Robustness: Subsample of Neighborhoods with Over 75\% Coverage}

Effects of Redlining - Pre: 1940; Post: 1970

\begin{tabular}{|c|c|c|c|c|}
\hline & $\begin{array}{c}(1) \\
\text { Log Total Units }\end{array}$ & $\begin{array}{c}(2) \\
\log \text { Pop/sqmi }\end{array}$ & $\begin{array}{c}(3) \\
\text { Pct. Black }\end{array}$ & $\begin{array}{c}(4) \\
\text { Pct. OwnerOcc }\end{array}$ \\
\hline Post40 X Redlined & $\begin{array}{c}-0.178^{* * *} \\
(0.028)\end{array}$ & $\begin{array}{c}-0.199^{* * *} \\
(0.037)\end{array}$ & $\begin{array}{c}0.009 \\
(0.043)\end{array}$ & $\begin{array}{l}-0.004 \\
(0.009)\end{array}$ \\
\hline Post-1940 & $\begin{array}{c}0.139^{* * *} \\
(0.032)\end{array}$ & $\begin{array}{c}-0.085^{* *} \\
(0.040)\end{array}$ & $\begin{array}{c}0.307^{* * *} \\
(0.036)\end{array}$ & $\begin{array}{c}0.059^{* * *} \\
(0.016)\end{array}$ \\
\hline Redlined & $\begin{array}{c}0.045 \\
(0.035)\end{array}$ & $\begin{array}{l}0.073^{*} \\
(0.037)\end{array}$ & $\begin{array}{c}0.089^{* * *} \\
(0.030)\end{array}$ & $\begin{array}{c}-0.039^{* * *} \\
(0.014)\end{array}$ \\
\hline $\begin{array}{l}\text { Observations } \\
R^{2} \\
\text { Mean }\end{array}$ & $\begin{array}{c}1496 \\
0.093 \\
7.17\end{array}$ & $\begin{array}{c}1496 \\
0.216 \\
9.80\end{array}$ & $\begin{array}{c}1496 \\
0.405 \\
.24\end{array}$ & $\begin{array}{c}1496 \\
0.261 \\
.35\end{array}$ \\
\hline \multicolumn{5}{|c|}{$\begin{array}{l}\text { Standard errors in parentheses } \\
\text { All specifications include controls, border segment FE, city-by-year FE and cluster SEs at city level } \\
{ }^{*} p<.10,{ }^{* *} p<.05,{ }^{* * *} p<.01 \\
\text { Effects of Repeal - Pre: 1940-1970; Post: 1980-2010 }\end{array}$} \\
\hline & $\begin{array}{c}(1) \\
\text { Log Total Units }\end{array}$ & $\begin{array}{c}(2) \\
\log \text { Pop/sqmi }\end{array}$ & $\begin{array}{c}(3) \\
\text { Pct. Black }\end{array}$ & $\begin{array}{c}(4) \\
\text { Pct. OwnerOcc }\end{array}$ \\
\hline Post70 X Redlined & $\begin{array}{c}-0.189^{* * *} \\
(0.024)\end{array}$ & $\begin{array}{c}-0.231^{* * *} \\
(0.032)\end{array}$ & $\begin{array}{l}-0.044^{*} \\
(0.022)\end{array}$ & $\begin{array}{c}0.019^{* * *} \\
(0.006)\end{array}$ \\
\hline Post-1970 & $\begin{array}{l}-0.047 \\
(0.042)\end{array}$ & $\begin{array}{c}-0.302^{* * *} \\
(0.077)\end{array}$ & $\begin{array}{c}0.265^{* * *} \\
(0.036)\end{array}$ & $\begin{array}{l}0.017^{*} \\
(0.009)\end{array}$ \\
\hline Redlined & $\begin{array}{c}0.066 \\
(0.047)\end{array}$ & $\begin{array}{c}0.118^{* * *} \\
(0.042)\end{array}$ & $\begin{array}{c}0.123^{* * *} \\
(0.042)\end{array}$ & $\begin{array}{c}-0.046^{* * *} \\
(0.016)\end{array}$ \\
\hline Observations & 4488 & 4488 & 4488 & 4488 \\
\hline$R^{2}$ & 0.174 & 0.244 & 0.252 & 0.119 \\
\hline Mean & 7.08 & 9.53 & .4 & .37 \\
\hline
\end{tabular}

Standard errors in parentheses

All specifications include controls, border segment FE, city-by-year FE and cluster SEs at city level ${ }^{*} p<.10,{ }^{* *} p<.05,{ }^{* * *} p<.01$ 


\subsection{Race in Border Tracts vs. All Red and Yellow Tracts}

Red-Yellow Border Tracts (L) vs All Red and Yellow Tracts (R)
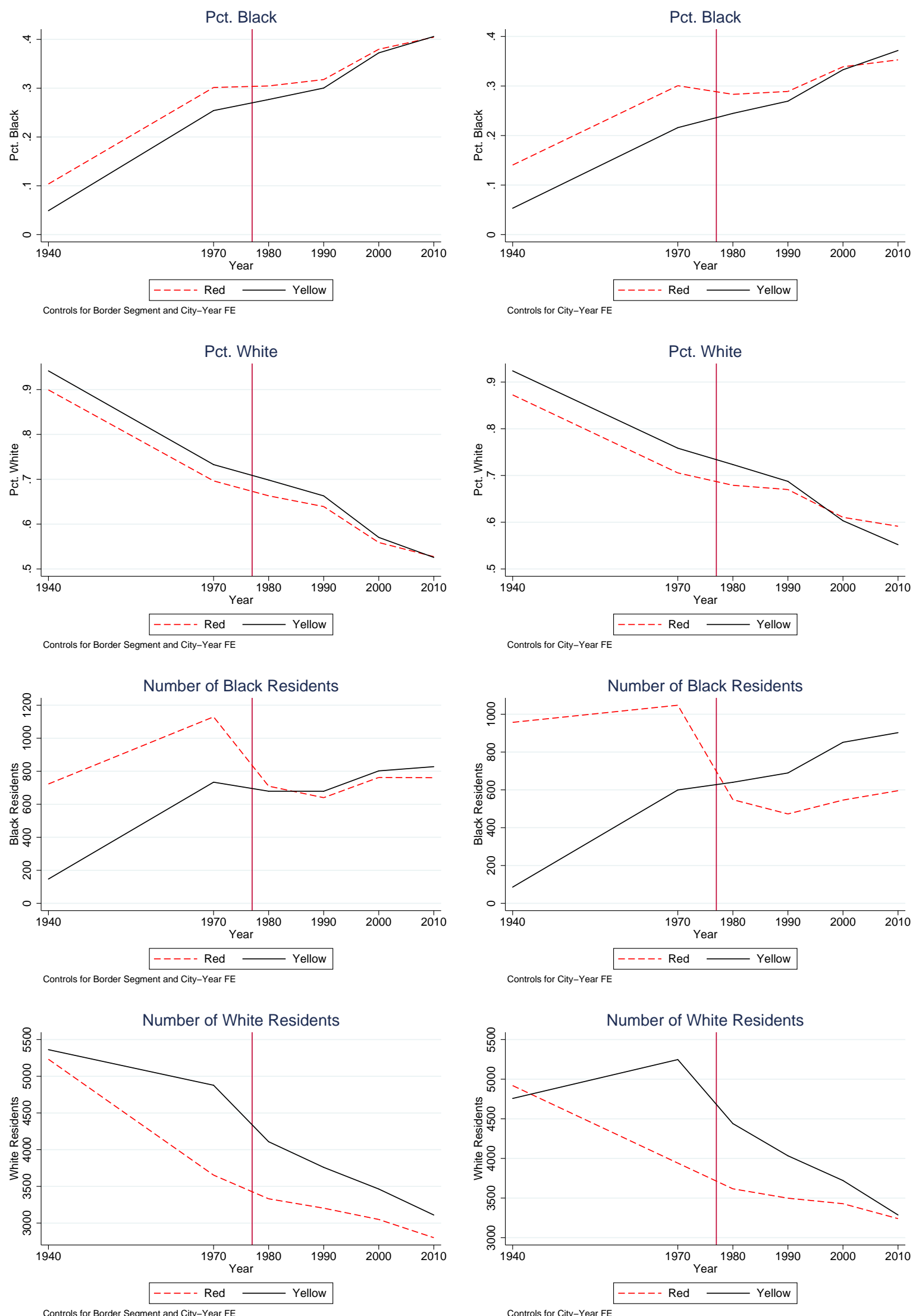


\subsection{Boundary Analysis for Other HOLC Grade Combinations}

\section{Yellow (Grade C) vs. Blue (Grade B) Border Tracts}
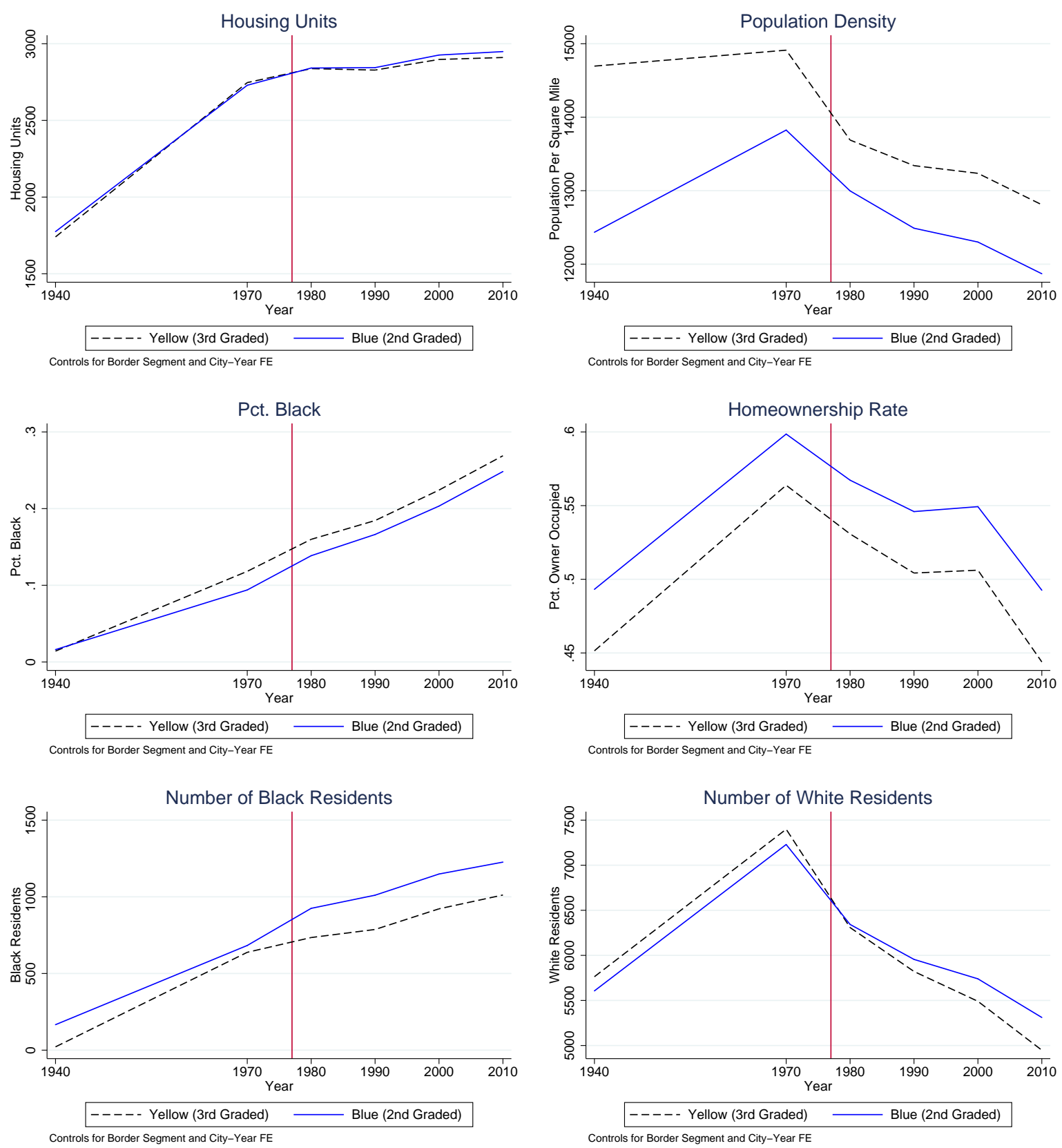
Blue (Grade B) vs. Green (Grade A) Border Tracts
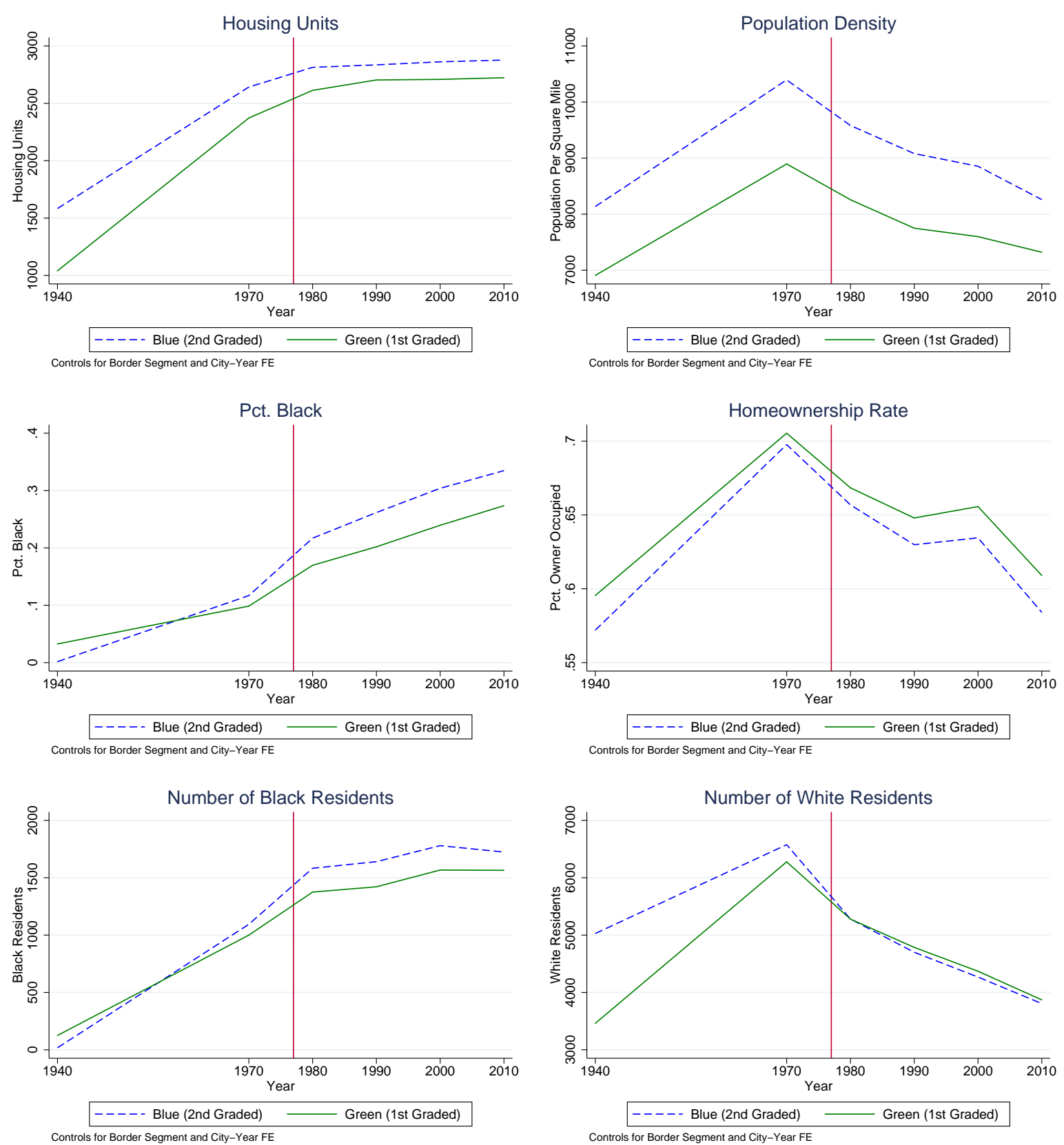


\section{Red (Grade D) vs. Blue (Grade B) Border Tracts}
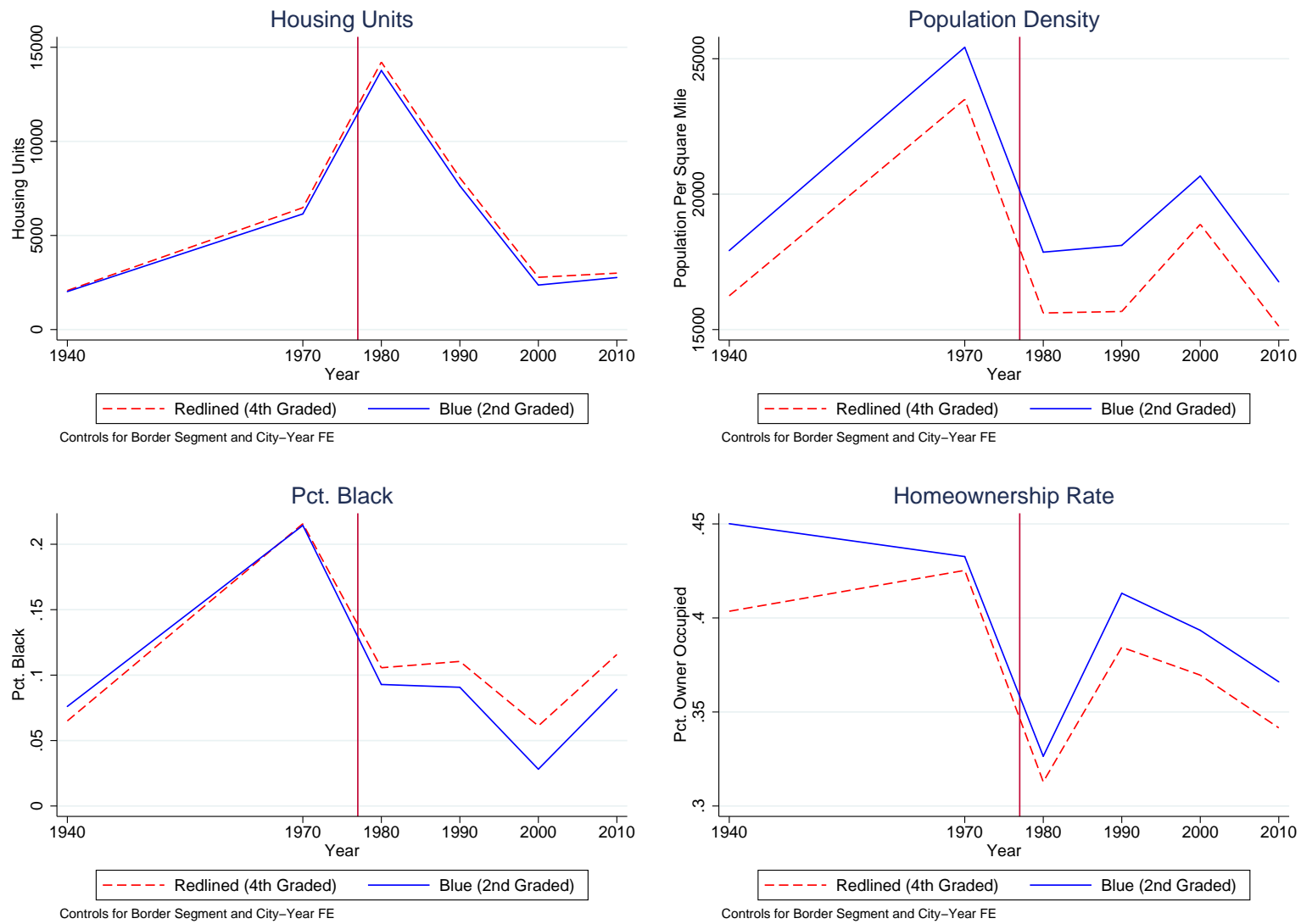

\subsection{Segregation and White Flight}

The following subsection focuses specifically on racial segregation and movement across Grade D and Grade C tracts from 1940 through 2010. Importantly, the data are a panel of census tracts without migration in or outflow data; I of course cannot track individuals' movement over time. Table 6 presents difference-in-differences results for border neighborhoods between 1940 and 1970. During this time period, HOLC redlining had no differential impact on neighborhood's share of black or white residents, or the number of black residents. In other words, tracts on the red-yellow boundary remained about as racially segregated between 1940 and 1970 . Redlining does, however, seem to have a differential effect on the number of white residents, as the implementation of the HOLC policy is associated with almost 1,100 fewer white people (about 22 percent of the mean of white residents per tract) residing in credit-restricted areas in 1970 compared to 1940. There is no effect on the shares due to the overall population decline in these areas (see Table 5 column 2 or the top-right of Figure 7), which column 4 confirms is wholly driven by the exodus of white residents in border areas. 
Table 7: Effect of Redlining on Neighborhood Racial Composition: 1940-1970

\begin{tabular}{lcccc}
\hline & $(1)$ & $(2)$ & $(3)$ & $(4)$ \\
& Pct. Black & Black Pop & Pct.White & White Pop \\
\hline Post40 X Redlined & -0.008 & -180.006 & 0.006 & $-1093.845^{* *}$ \\
& $(0.016)$ & $(179.373)$ & $(0.016)$ & $(412.367)$ \\
Post-1940 & $0.205^{* * *}$ & $586.720^{* * *}$ & $-0.209^{* * *}$ & $-484.801^{* * *}$ \\
& $(0.004)$ & $(48.920)$ & $(0.004)$ & $(112.464)$ \\
Redlined & $0.036^{* * *}$ & $326.953^{* * *}$ & $-0.017^{*}$ & -21.734 \\
& $(0.011)$ & $(71.950)$ & $(0.009)$ & $(287.750)$ \\
\hline Observations & 4108 & 4110 & 4108 & 4110 \\
$R^{2}$ & 0.373 & 0.229 & 0.474 & 0.129 \\
Sample & Border Only & Border Only & Border Only & Border Only \\
Mean & .19 & 1088.7 & .8 & 5078.41 \\
\hline Standard errors in parentheses & \multicolumn{3}{c}{} \\
All specifications include controls, border segment FE, city-by-year FE and cluster SEs at city level \\
${ }^{*} p<.10,{ }^{* *} p<.05,{ }^{* * *} p<.01$
\end{tabular}

Figure 8 tracks the effects of HOLC redlining and its repeal (in 1977, marked by the vertical red line) on border neighborhood racial composition from 1940 through 2010. The panels on the left side are difference-in-differences predicted estimates for tracts bordering the Red-Yellow boundary line, while the graphs on the right include all tracts within a half-mile radius of the border. Both sets of estimates control for tract level observables in 1940, border segment fixed effects, and city-by-year interacted fixed effects (as is standard in the preferred specification throughout this paper) 34

The figures in the first row show results for the number of black residents. Both left and right panels tell a similar story: between 1940 and 1970, the black population increased at a similar rate in both red and yellow graded neighborhoods close to the HOLC boundary. Importantly, there were always more black residents in the redlined areas than the control neighborhoods. After redlining was made formally illegal in the mid-1970s, the number of black families living in redlined areas dropped precipitously, from about 1,100 in redlined border tracts in 1970 to about 700 in those same areas in 1980. The number of black residents equalized on either side of the boundary, as the black and red-dotted lines in the top left figure are nearly identical from 1980 through 2010. When redlining became illegal, perhaps black families living in creditrestricted areas for the first time were able to secure housing in higher quality urban and/or suburban areas without being discriminated against. It does not appear that black families simply moved across the red-yellow boundary after 1977 .

\footnotetext{
${ }^{34} \overline{\text { For tracts within a half-mile radius but not }}$ on the boundary line itself, I identify the closest border line segment and use that in the fixed effect.
} 
Figure 9: Effect of Redlining and Repeal on Racial Composition, 1940-2010

Red-Yellow Border Tracts (L) vs Tracts Within 0.5 Miles of Red-Yellow Border $(R)$
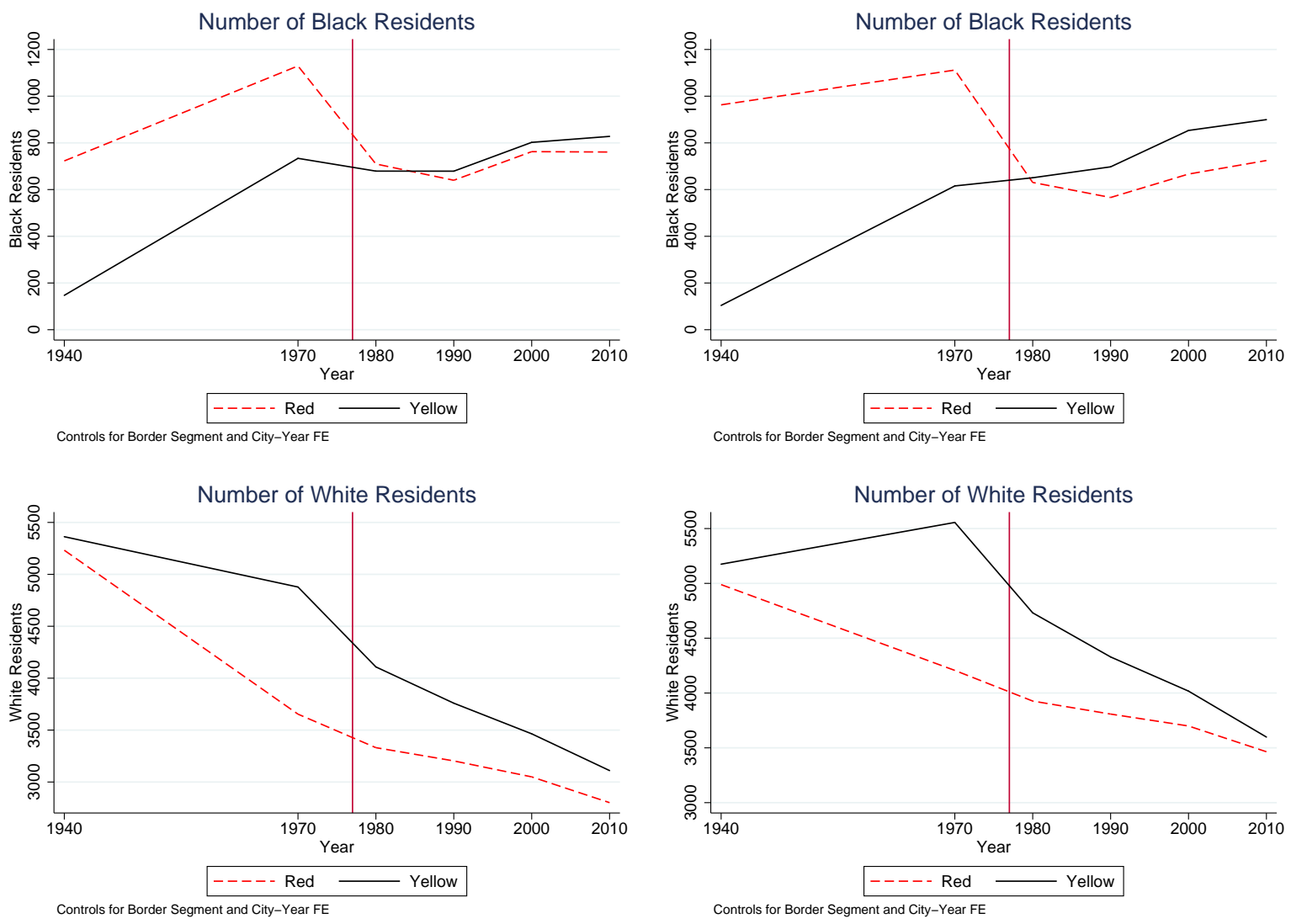

The panels in the second row show that the number of white residents in redlined areas declined in each decade from 1940 through 2010. This trend is consistent with the white flight of families living in crowded, urban, mixed-race neighborhoods moving to more sparsely populated neighborhoods in the post-War period. The white population in boundary yellowgraded areas fell between 1940 and 1970; but over the same period, the white population living in yellow-graded areas within 0.5 miles of the boundary actually increased (bottom right figure). This suggests that white migration out of redlined areas may have been more gradual: first from border neighborhoods to tracts not adjacent to the boundary and then to suburban areas after 1970. Notice the white population in yellow-graded areas within a half mile of the red-yellow boundary does not actually begin to decline until after mortgage lending discrimination becomes illegal in 1977. 